\title{
DEVELOPMENT AND EXTRAPOLATION OF AN UNDERGRADUATE \\ LABORATORY EXPERIMENT TO AN ELASTOMERIC SPINAL MUSCULAR ATROPHY BRACE
}

\author{
A Project Report \\ presented to \\ the Faculty of California Polytechnic State University, \\ San Luis Obispo
}

In Partial Fulfillment of the Requirements for the Degree

Master of Science in Polymers and Coatings (Chemistry Department)

by

Richard Sterling Brose

June 2011 
(C) 2011

Richard Sterling Brose

ALL RIGHTS RESERVED 
COMMITTEE MEMBERSHIP

TITLE:

DEVELOPMENT AND EXTRAPOLATION OF AN

UNDERGRADUATE LABORATORY

EXPERIMENT TO AN ELASTOMERIC SPINAL

MUSCULAR ATROPHY BRACE

AUTHOR: $\quad$ Richard Sterling Brose

DATE SUBMITTED: June 2011

COMMITTEE CHAIR: Dr. Philip J. Costanzo, Assistant Professor

COMMITTEE MEMBER: $\quad$ Dr. Raymond H. Fernando, Professor

COMMITTEE MEMBER: Dr. Chad Immoos, Associate Professor 


\title{
ABSTRACT \\ DEVELOPMENT AND EXTRAPOLATION OF AN UNDERGRADUATE LABORATORY EXPERIMENT TO AN ELASTOMERIC SPINAL MUSCULAR ATROPHY BRACE
}

\author{
Richard Sterling Brose
}

Ever since the advent of polymer science, polyurethanes have played a huge role in the industrial world. They have been used in endless applications from furniture padding to aircraft coatings, to binders for insensitive munitions. It is therefore important that the chemistry of polyurethanes is well understood as well as the ability to draw relationships between the raw materials selected and the end-use properties of the polymer. Because of the multitude of practical applications, the development of an undergraduate polymer chemistry laboratory focused on polyurethane elastomers is developed and described herein. Polymer chemistry students are exposed to hydroxyterminated polybutadiene (HTPB) polyols as well as di- and multifunctional isocyanates for use in a tin-catalyzed reaction. The effect of catalyst concentration and crosslinking agent on cure time, prepolymer structure on end-use properties, and the effect of crosslink density on physical properties are explored. Students also receive a very important introduction to statistical experimental design. They learn when using statistical experimental design is necessary, and they learn how to manipulate, analyze, and interpret data using two-way ANOVA in Minitab.

The development of the lab experiment also led to extrapolating the use of polyurethane elastomers into a new application, the development of a polyurethane 
spinal muscular atrophy (SMA) brace. SMA is a neurodegenerative disorder that results in the mutation or deletion of the spinal motor neuron gene, resulting in the atrophy of a subject's spine muscles throughout the continuation of their life. These patients are therefore forced to wear a brace for the entirety of their lives. The current brace technology in use by SMA patients is limited by the fact that SMA affects a very small amount of the population and therefore it is not cost-effective for industry to develop a brace technology designed for these patients. Scoliosis braces such as thoracolumbrosacral orthoses (TLSOs) are too hard and too uncomfortable for patients with SMA; therefore, the polyurethane elastomer was extrapolated to develop a brace with more flexibility and more durability. Two generations of polyurethane elastomeric brace were developed and evaluated by a subject and family with an SMA background. The brace is a much improved technology to the TLSO braces and provides more flexibility, more mobility, greater comfort, and superior modularity to the old technology. An instruction manual is also included with a step-by-step process of how to reproduce the brace.

Keywords: polyurethane, elastomer, spinal muscular atrophy, polymer, two-way ANOVA, polymer laboratory experiment 


\section{ACKNOWLEDGEMENTS}

I would first like to acknowledge the Cal Poly Polymers and Coatings Program for funding this research and the Cooper Family for their support and guidance. 
TABLE OF CONTENTS

Page

LIST OF TABLES

xii

LIST OF FIGURES

xiii

1. POLYURETHANES 1

1.1. INTRODUCTION 1

1.2. DISCOVERY / HISTORY OF POLYURETHANES 2

1.3. STEP GROWTH POLYMERIZATIONS

1.4. CHEMISTRY OF POLYURETHANES 6

1.4.1. SIDE REACTIONS

1.5. ELASTIC POLYURETHANES 10

1.5.1. ADVANTAGES OF ELASTIC POLYURETHANES OVER 10 CONVENTIONAL RUBBER

1.5.2. APPLICATIONS OF ELASTIC POLYURETHANES 11

1.6. RAW MATERIALS 11

1.6.1. POLYOLS 11

1.6.1.1. LOW MW POLYOLS 12

$\begin{array}{lll}\text { 1.6.1.2. } & \text { OLIGO-POLYOLS } & 12\end{array}$

1.6.1.3. TAILORING OLIGO-POLYOLS 13

$\begin{array}{lll}\text { 1.6.1.4. POLYBUTADIENE POLYOLS } & 14\end{array}$

1.6.2. DIISOCYANATES / POLYISOCYANATES 15 
1.6.2.1. FORMATION OF ISOCYANATES 16

1.7. SAFETY CONCERNS WITH POLYURETHANES 16

$\begin{array}{ll}\text { REFERENCES FOR CHAPTER } 1 & 19\end{array}$

2. DEVELOPMENT OF UNDERGRADUATE POLYMER SYNTEHSIS 20

LABORATORY EXPERIMENT

2.1. BACKGROUND 20

2.2. GOALS 22

2.3. STATISTICAL METHODS 22

2.3.1. IMPORTANCE OF STATISTICS IN EXPERIMENTAL 22 DESIGN

2.3.2. OBSERVATIONAL STUDY VERSUS EXPERIMENTAL 23 STUDY

2.3.3. BUILDING AN EXPERIMENTAL STUDY 23

2.3.4. TWO WAY ANALYSIS OF VARIANCE 25

2.4. EXPERIMENTAL METHODS AND MATERIALS 26

2.4.1. RAW MATERIALS 26

2.4.2. GENERAL EXPERIMENTAL SCHEME FOR HTPB 27

ELASTOMERS

2.4.3. EFFECT OF CATALYSTS CONCENTRATION ON CURE 27 TIME

2.4.4. EFFECT OF CROSSLINKING AGENT ON CURE TIME 
2.4.5. EFFECT OF THE STRUCTURE OF THE PREPOLYMER 28

2.4.6. EFFECT OF CROSSLINKING DENSITY 28

2.4.7. STATISTICAL RANDOMIZED DESIGN EXPERIMENT 29

2.5. RESULTS AND DISCUSSION 31

2.5.1. EFFECT OF CATALYSTS CONCENTRATION ON CURE 31 TIME

2.5.2. EFFECT OF CROSSLINKING AGENT ON CURE TIME 32

2.5.3. EFFECT OF THE STRUCTURE OF THE PREPOLYMER 33

2.5.4. EFFECT OF CROSSLINKING DENSITY 34

2.5.5. TWO WAY ANOVA RESULTS 36

2.6. HAZARDS 39

2.7. CONCLUSION 39

REFERENCES FOR CHAPTER 2

3. DESIGN AND DEVELOPMENT OF A POLYURETHANE TORSO 41 BRACE FOR PATIENTS SUFFERING FROM SPINAL MUSCULAR ATROPHY

3.1. SPINAL MUSCULAR ATROPHY 41

3.2. CURRENT TECHNOLOGY 43

3.2.1. FULL TORSO BRACES 43

3.2.1.1. TLSO BRACES 43

3.3. GOAL OF PROJECT 44

3.4. SCALE UP METHODS AND MATERIALS 46

3.4.1. MATERIALS 46 
3.4.2. RSB-A-5 - CIRCULAR GEL 46

3.4.3. RSB-A-7 - THICKER CIRCULAR GEL 46

3.4.4. RSB-A-9 \& RSB-A-11 - ALUMINUM MOLDS 46

3.4.5. RSB-A-15 - RECTANGULAR ELASTOMER 47

3.4.6. RSB-A-17 - RECTANGULAR ELASTOMER W/VACUUM 47

3.4.7. RSB-A-19 - COPPER WIRE FILLER ADDED 47

3.4.8. RSB-A-21 48

3.4.9. RSB-A-23 48

3.4.10. RSB-A-27 - INCORPORATION OF DIRECTIONAL 49 STRENGTHENER

3.5. SCALE UP - RESULTS AND DISCUSSION 49

3.6. BRACE MANUFACTURING 55

3.6.1. MATERIALS

3.6.1.1. PROVIDED MATERIALS 55

3.6.1.2. ACQUIRED MATERIALS 55

3.6.2. EXPERIMENTAL 56

3.6.3. SYSTEM DESIGN SCHEMATIC $-1^{\text {ST }}$ GENERATION 56 BRACE

3.6.4. RESULTS AND DISCUSSION 57

3.6.4.1. THERMOFORMING WITH POLYETHYLENE 57 TEREPHTHALATE (PET)

3.6.4.2. DEVELOPMENT STEPS $-1^{\mathrm{ST}}$ GENERATION 58 BRACE 
3.6.4.3. FIRST GENERATION FEEDBACK 61

3.6.4.4. SYSTEM DESIGN SCHEMATIC $-2^{\mathrm{ND}}$ GENERATION 62

3.6.4.5. $2^{\mathrm{ND}}$ GENERATION BRACE PRODUCTION 63

3.6.5. CONCLUSION 65

REFERENCES FOR CHAPTER $3 \quad 66$

4. CONCLUSION OF PROJECT 67

$\begin{array}{ll}\text { APPENDIX A - RAW DATA } & 70\end{array}$

$\begin{array}{ll}\text { APPENDIX B - STATISTICAL OUTPUT } & 71\end{array}$ 
LIST OF TABLES $\quad$ Page

$\begin{array}{lll}1.1 & \text { Health effects of diisocyanates } & 17\end{array}$

2.1 Important properties of raw materials 26

2.2 Treatment combinations for experimental study 29

2.3 Cure times of different crosslinking agents 32

2.4 Observations of polyurethanes with varying prepolymer 33

2.5 Swelling results 35

3.1 Descriptions of SMA types 41

A1 Effect of catalyst amount on cure time $\quad 80$

A2 Effect of curing agent on cure time $\quad 80$

A3 Swelling Raw Data 80 
1.1 A general reaction of urethane formation. An isocyanate reacting with 1 an alcohol forms a urethane or carbamate linkage.

1.2 Otto Bayer, the discoverer of polyurethanes. 2

1.3 The molecular structures of 1,6-hexamethylene diisocyanate (HMDI) 3 (a) and toluene diisocyanate (TDI) (b).

1.4 A pie chart depicting the different applications of polyurethanes and 4 the percentage of the market share.

1.5 A generic procedure for step-growth polymerization.

1.6 The Lewis acid mechanism for tin-catalyzed urethane formation is 6 shown.

1.7 Structure of dibutyl tin dilaurate.

1.8 The hard and soft segments of a generic polyurethane are shown.

1.9 The Hofmann rearrangement depicting an isocyanate reacting readily 8 with water to produce carbon dioxide, which is a blowing agent in polyurethane formation.

1.10 The general formula of oligo-polyols used in polyurethanes. 12

1.11 A generic structure of a hydroxyterminated polybutadiene is shown $\quad 14$ where $\mathrm{x}, \mathrm{y}$, and $\mathrm{z}$ represent the ratios of 1,4-trans, 1,2-, and 1,4-cis addition of the butadiene.

1.12 Structures of toluene diisocyanate, hexamethylene diisocyanate, and isophorone diisocyanate are shown.

2.1 The experimental setup is shown (right) along with a zoomed in picture of a curing polyurethane elastomer (left). 
2.2 Qualitative viscosity, as determined by a tongue depressor versus cure 31 time (min).

2.3 The structures of HMDI, IPDI, and generic DESMODUR. 32

2.4 The swelling trends for the three formulations in THF over 120 minutes. 36

2.5 The main effects plot for cure time with both catalyst treatment and 37 curing agent treatment are shown.

2.6 The interactions plot for catalyst and curing agent with respect to cure 38 time is shown.

3.1 A generic TLSO brace is shown. It is made of two parts and provides 44 360 degrees of support.

3.2 The general reaction scheme to form an HTPB polyurethane elastomer 45 is shown.

3.3 RSB-A-5. Round polyurethane gel elastomer. 49

3.4 The 200 g rectangular sample, RSB-A-15, is shown. 51

3.5 RSB-A-19. The incorporation of copper wire into the matrix of the gel. 52

3.6 The modified copper wire exit ports are shown. On the left, the PUR 52 was removed and replaced by RSB-A-21, while the right shows RSB-A-21 on the surface.

3.7 Modified RSB-A-17. Rectangular PUR mold with epoxy filler present. 53

3.8 A schematic displaying the manufacturing process of the $1^{\text {st }}$ generation 56 brace is shown.

3.9 The end of the thermoforming process is shown. The PET outer shell 57 has been formed around the expanded plaster mold.

3.10 The outer PET shell with thumbtack spacers is shown in the tub of 58 sand. The tacks maintain a $1 / 2$ in minimum elastomer thickness.

3.11 An image of the setup immediately before the mold is poured. The 59 plaster is protected by a PET layer, and the inner mold is resting upon 
the thumbtacks.

3.12 The epoxy connecting both sides of the brace is shown. 60

3.13 The complete first generation brace is shown. Velcro straps are 60 adjustable and can provide semi-modular support.

3.14 A block diagram showing the production schematic of the $2^{\text {nd }} \quad 62$ generation brace is shown.

3.15 The vinyl foam weatherseal, added in two layers is shown. Epoxy is 63 used to seal the layers on the outer side.

3.16 The incorporation of gutter mesh is shown. There are two distinct layers, one on the bottom and one suspended in the middle of the thumbtack heads.

3.17 The $2^{\text {nd }}$ generation brace is shown from three views: back (left), 64 top-down (middle), and front (right).

3.18 The subject wearing the brace. 


\section{Polyurethanes}

\subsection{Introduction}

Since its discovery, polyurethane (PUR) chemistry has been used in a variety of different chemical and industrial fields. Because of its chemistry and tunable properties, polyurethanes are one of the most versatile polymer systems today. The reaction was discovered in the 1940s by Heinrich Rinke and Otto Bayer. ${ }^{1}$ The multitude of everyday applications has arisen from the 'simple' nature of the chemistry behind polyurethanes, making the product easily scalable to industrial applications. Urethanes are a classification of reaction characterized by the presence of a urethane, or carbamate, linkage. A urethane linkage is shown in Figure 1.1 with a carbonyl flanked on one side by a nitrogen and the other by an oxygen. This functional group is formed by the reaction of an organic isocyanate with a hydroxyl group as shown in Figure 1.1. Polyurethanes

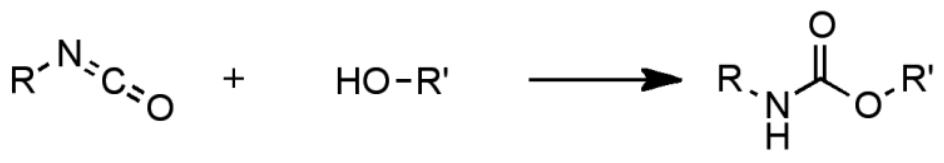

Figure 1.1. A general reaction of urethane formation. An isocyanate reacting with an alcohol forms a urethane or carbamate linkage.

utilize this same functional group but in a repeating fashion wherein a diol monomer could react with a diisocyanate monomer in order to form a continual long-chain macromolecule or polymer. The types of monomer units can be tailored to give very different chemical and physical properties, and the degree of polymerization can also be adjusted depending on the desired properties. ${ }^{2}$ This chapter describes the history and chemistry, and applications of polyurethanes as a whole. Special discussion is directed at 
polyurethane elastomers, the raw materials in their synthesis, their physical properties, and hazards associated with using polyurethane chemistry.

\subsection{Discovery / History of Polyurethanes}

Thousands of years before the discovery of polymers, techniques such as coating, bonding, and sealing were performed using purely natural resins, fats, or oils. An example of one such natural material is shellac, which is a natural resin secreted by the female lac insect. Shellac has been used for centuries in India and Thailand as a hydrophobic coating for surfaces. ${ }^{1}$ It has been discovered that many ancient cultures such as the Babylonians, Egyptians, and Ancient Greeks and Romans used animal hides and bones in ancient adhesives as far back as $6000 \mathrm{BC}$. During the Middle Ages, there was not much development in the field of polymer science and adhesives. However, the invention of the printing press by Johannes Gutenberg led to a need for better adhesives in order to improve book binding technology. ${ }^{3}$ In 1907-1909 a Belgian chemist by the name of Leo Baekeland developed one of the first plastics made from synthetic/natural components. Dr.

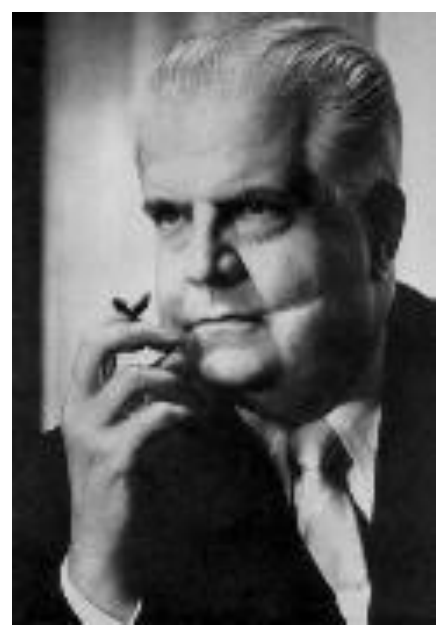

Figure 1.2. Otto Bayer, the discoverer of polyurethanes.

Baekeland originally set out to find a replacement for shellac, and around this time, chemists had begun to recognize that many natural fibers and resins were in fact polymers. Baekeland produced the first soluble phenol-formaldehyde (PF) shellac called Novolak, which was never successful; however, its discovery led to the discovery of 
Bakelite resin, the first commercially used PF resin in the early 1920s. ${ }^{4}$ It was not until the 1930s when synthetic polymers were discovered.

Wallace Carothers' invention of Nylon 6,6 in the mid 1930s was a pioneering discovery in the synthetic polymer industry. Only a few years following that discovery, Heinrich Rinke successfully synthesized 1,6-hexamethylene diisocyanate (HMDI) and Otto Bayer, shown in Figure $1.2^{5}$, utilized HMDI in the development of the polyurethane addition process. ${ }^{2}$ For that discovery, Otto Bayer has been established as the discoverer of polyurethanes. Of the many types of polyurethanes produced today, initial research focused on polyurethane fibers, while polyurethane foams were produced later in the $20^{\text {th }}$

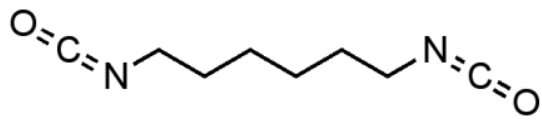

a<smiles>Cc1ccc(N=C=O)cc1N=C=O</smiles>

b

Figure 1.3. The molecular structures of 1,6-hexamethylene diisocyanate (HMDI) (a) and toluene diisocyanate (TDI) (b).

century. ${ }^{1}$ In the late 1950s, the first polyurethane coatings were developed. Bayer and his team were able to determine that modifications of isocyanates and incorporation of those isocyanates into alkyd resins would allow for improved physical properties.

The use of molecular isocyanates, HMDI, and toluene diisocyanate (TDI), did not provide quite the strength that was needed in a coating; therefore, the development of low-monomer polyisocyanates was explored. Most of the initial work in the development of these polyisocyanates utilized toluene diisocyanate; however, due to its aromatic character, exposure to UV radiation caused the coating to significantly yellow. For this reason, incorporation of TDI based polyisocyanates were limited to indoor applications. ${ }^{1}$ The molecular structures of both HMDI and TDI are shown in Figure 1.3 for reference. The development of aliphatic polyisocyanates later allowed for a broader 
range of uses for polyurethanes. The Desmodur N series, developed by Bayer MaterialScience, was the first type of polyisocyanates based on HMDI. It was developed in the early 1960s alongside Desmophen, DuPont's proprietary polyol; together, Desmodur and Desmophen were coined the 'DD' two component coating system. ${ }^{6}$ Once introduced, this series of $2 \mathrm{~K}$ coatings replaced the traditional alkyd resins. The large automotive industry was the first to adopt these new $2 \mathrm{~K}$ coatings because quality of the coating was equivalent to the alkyd resins; however, the performance of these coatings when dried at room temperature was equivalent to the performance of the alkyd coatings after being baked. ${ }^{3}$ The development of a coating that could be placed on a large vehicle without baking was nearly priceless for the industry. With this new advancement, a vehicle could be coated once assembly was complete increasing the overall durability of the coating and saving time as well. Today, two component polyurethane coatings are still the predominant coating in the automotive and large vehicle industry.

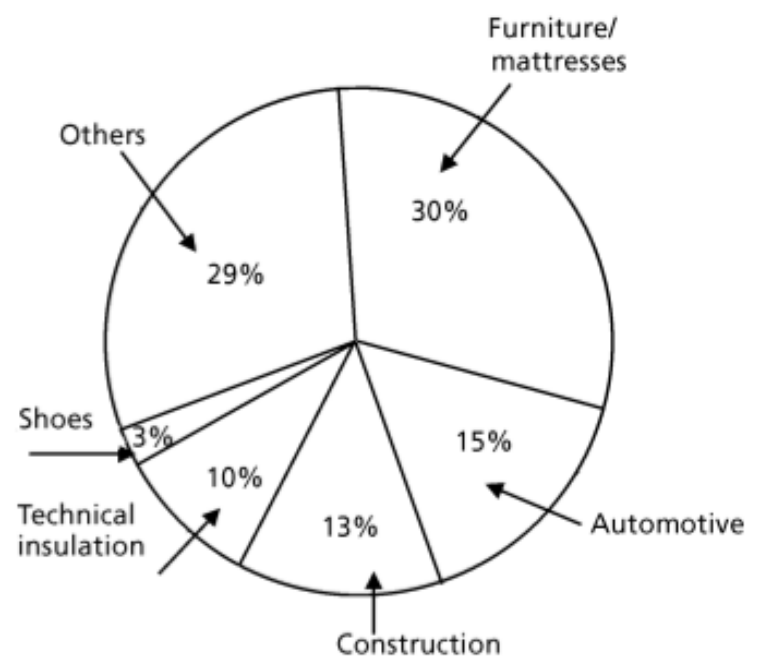

Figure 1.4. A pie chart depicting the different applications of polyurethanes and the percentage of the market share.
The use of polyurethanes in other applications such as adhesive systems was kick-started in the 1950s as well with the development of new hydroxyl based urethanes. Bayer MaterialScience also developed the Desmodur R series, a trifunctional isocyanate crosslinking agent. 
Today, polyurethanes make up about $5 \%$ of polymer plastics applications. Figure 1.4 is a representation of all of the different applications of polyurethanes today. As one can see, nearly $30 \%$ of polyurethanes are used for small, specific applications denoted by the other category. ${ }^{3}$ Even with the ever-increasing 'green' initiatives, polyurethanes are still at a competitive advantage. There are many solvent-free, low-VOC, and water-based formulations of polyurethanes that allow for their continued use in a variety of fields.

\subsection{Step-Growth Polymerizations}

One of the major benefits of polyurethane chemistry is the simplicity of the chemistry and the scalability of the reactions. Polyurethanes are synthesized via stepgrowth polymerization; however, unlike many step-growth polymerization reactions, there are no byproducts of the polymerization. ${ }^{7}$ A step-growth polymerization is

$$
\mathrm{A}-\mathrm{A}+\mathrm{B}-\mathrm{B} \longrightarrow[\mathrm{A}-\mathrm{AB}-\mathrm{BA}-\mathrm{AB}-\mathrm{B}+
$$

Figure 1.5. A generic procedure for step-growth polymerization.

characterized by the presence of two difunctional monomer units that react with the other to form long chains of molecules. If branching is required, multifunctional monomers can be used. Figure 1.5 shows a generic example of a step-growth process where monomer A and monomer $\mathrm{B}$ react forming a generic polymer. The two monomer units react in a 1:1 stoichiometric ratio until all reagents are consumed. During the polymerization, the chains build slowly, relative to free radical polymerization, in a stepwise fashion. Monomers initially combine to give dimers, and trimers also combine with other monomers, dimers, and trimers in order to form higher order oligomers. It is for this reason that the molecular weight of step-growth polymers stay very low until nearly 
$100 \%$ conversion. It should also be noted that slight modifications in the stoichiometric ratios have a very large effect on the theoretical molecular weight.

It is a common misconception that has resulted in polyurethanes being lumped into the category of condensation reactions. Condensation reactions occur when there is an elimination or 'condensation' of a specific group during the reaction. A common reaction utilizing condensation chemistry involves reacting acetic acid with alcohol in order to form ethyl acetate. In the reaction, water is lost; therefore, it is a condensation reaction. Polyurethanes have been incorrectly grouped with other condensation reactions because most step-growth polymerizations do result in a condensation product. ${ }^{2,7}$ Instead polyurethane chemistry should simply be referred to as an addition reaction.

\subsection{Chemistry of Polyurethanes}

As stated earlier, polyurethanes are the result of a step-growth polymerization between an isocyanate functional group and an alcohol functional group in the presence of a catalyst. Depending on the desired end properties, the functionality of the monomer

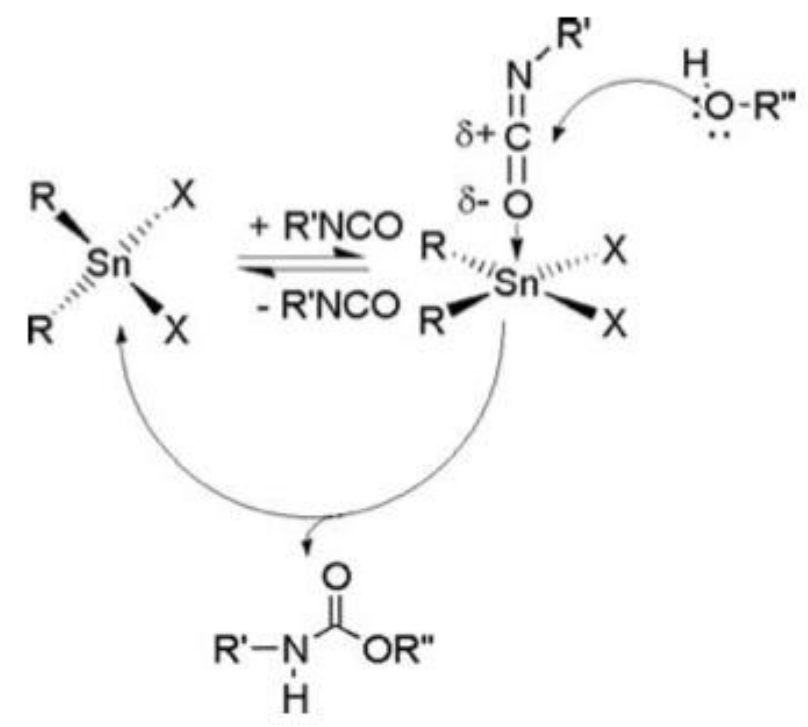

Figure 1.6. The Lewis acid mechanism for tin-catalyzed urethane formation is shown. 
units can change. For example, when toluene diisocyanate and hexamethylene diisocyanate react with hexamethylene diol; the planar, bulky structure of TDI makes the resulting polymer glassy at room temperature; however, the more TDI linkages that are replaced by HMDI linkages, the more flexible the material becomes at room temperature. Polyurethane synthesis must be performed in the presence of a catalyst for the most desirable results.

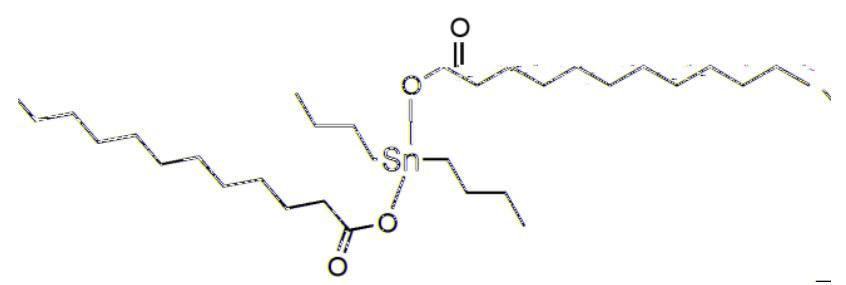

Figure 1.7. Structure of dibutyl tin dilaurate.

The organometallic catalysis mechanism is depicted in Figure 1.6. ${ }^{8}$ Lewis acid/base chemistry utilizing coordination to a tin catalyst complex is shown. The partial negative charge of the isocyanate carbonyl group coordinates with the metal center, assisting in the attack of the oxygen from an alcohol group onto the carbonyl of the isocyanate. Once the attack is complete, the resulting molecule, a urethane, uncoordinates from the metal center restoring the catalyst. Traditionally, dibutyl tin dilaurate (DBTDL)

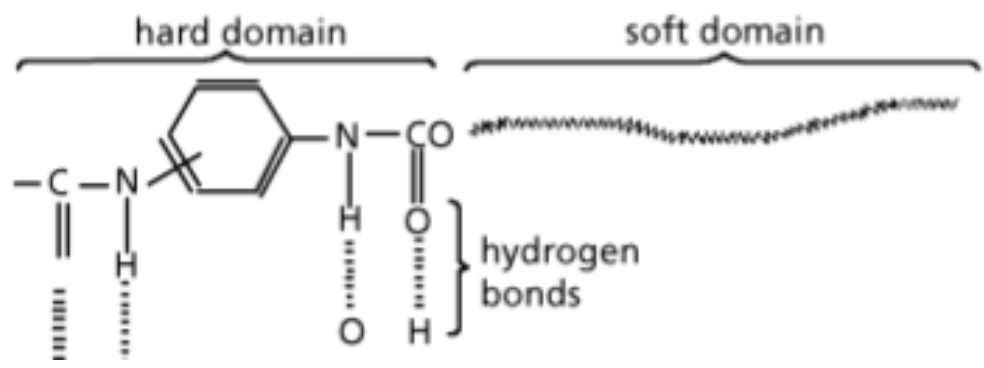

Figure 1.8. The hard and soft segments of a generic polyurethane are shown. 
is the tin catalyst used for polyurethane chemistry, and the structure is shown in Figure 1.7. DBTDL is one of the most widely used tin catalysts for polyurethane formation particularly in the field of adhesives and sealants, but it can also be used in the catalysis of polyurethane elastomer formation.

It should also be noted that there are hard segments and soft segments to every polyurethane. Due to the planar character of the urethane linkage and the surrounding isocyanate molecules, those are the hard segments while the diol or polyol used controls the 'soft' segment. This can be seen in Figure $1.8^{3}$, where the hard domain is accompanied by hydrogen bonding and planar geometry, while the soft domain is more linear and flexible. For this reason, the hard segments are sometimes said to form 'virtual' crosslinks through secondary bonds.

\subsubsection{Side Reactions}

The presence of side reactions in polyurethane synthesis is almost as important as the actual polymerization itself. These side reactions are responsible for the versatility of polyurethanes, specifically in the field of foams.

The most prevalent side reaction for polyurethane synthesis occurs in the presence of water. An isocyanate group will react readily with water to form a carbamic acid;

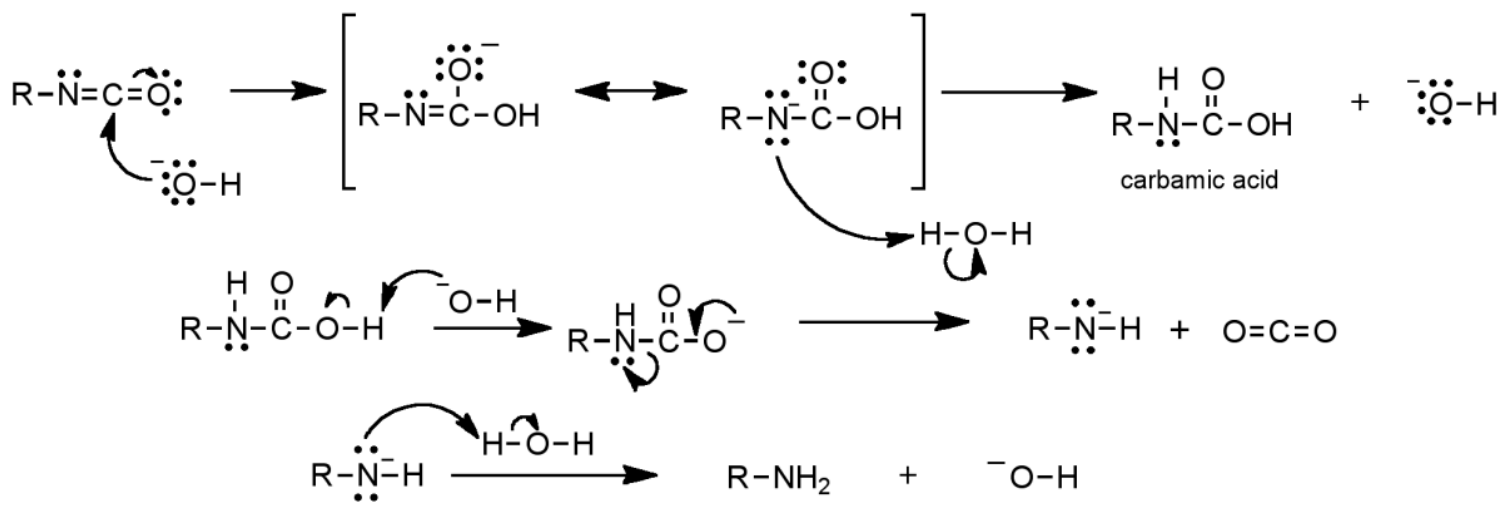

Figure 1.9. The Hofmann rearrangement depicting an isocyanate reacting readily with water to produce carbon dioxide, which is a blowing agent in polyurethane formation. 
however, carbamic acids are unstable and decompose forming carbon dioxide and an amine. This mechanism, known as the Hofmann rearrangement, is shown in Figure 1.9. A hydroxyl group from the water attacks the carbonyl of the isocyanate group. The carbonyl is restored, resulting in a shift of the electron density to the nitrogen. The lone pair on the nitrogen abstracts a proton from a water molecule forming the carbamic acid. The decarboxylation of the carbamic acid then follows. A hydroxyl group abstracts the acidic proton resulting in a deprotonated acid. The extra lone pair on the oxygen forms another double bond to the carbon, cleaving the nitrogen-carbon bond. Carbon dioxide is released and an amine is formed. ${ }^{9}$

The production of the carbon dioxide within the matrix of the polyurethane is known as a blowing agent because of its ability to expand the polymer system creating foam. Blowing agents vary from water to certain halo- and hydrocarbons and have a significant effect on the quantity and quality of the foam produced. Using water as a blowing agent has some other ramifications as well. The amine groups that are formed alongside the carbon dioxide will react with the isocyanate groups and form substituted urea. If enough water is present, polyurea will be formed. Due to the fact that water has such a low MW compared to the polyurethane, the \%wt of water in the solution will be very small; however the molar percent of water in solution may be substantial enough to produce a large amount of urea. The carbamic acid side reaction can be seen in Figure 1.9. It should also be noted that as this is a side reaction, the stoichiometric ratios of the main polymerization are affected because of it, and therefore an excess of isocyanate should be used if a blowing agent such as water will be incorporated into the formulation at some point. 


\subsection{Elastic Polyurethanes}

Elastic polyurethanes, generally with low crosslinking density, encompass a wide variety of materials. The types of polyurethanes that fall under this classification are semiflexible PUR foams, integral skin foams, flexible PUR foams, microcellular elastomers, adhesives, coatings, sealants, PUR elastomers, PUR fibers, and paints. The reason for this grouping is because all of these materials, like conventional rubber, have the ability to be elastomeric. ${ }^{10}$ Elastomeric materials are stretchy and can further be divided into two types, thermoplastic and thermoset depending on the chemistry and the processing of the materials. Elasticity of the material is dependent on how many chemical crosslinks are present in the elastomeric matrix. The higher the number of chemical crosslinks, the stronger the material, but the less elastomeric it is. Depending on the desired application, different raw materials can be selected to ensure the desired thermal, mechanical and chemical properties of a cured system.

\subsubsection{Advantages of Elastic Polyurethanes over Conventional Rubber}

There are many advantages to why polyurethane elastomers are much more efficient than conventional rubbers. From a processing standpoint, polyurethanes have low/medium capital costs, while the capital cost of rubbers is very high. Secondly, in the preparation stage, mixing of polyurethanes is much easier. There is no machine required, whereas conventional elastomers require an open mill and intensive mixing. Thirdly, the molds made from polyurethane are very lightweight whereas the conventional molds are very heavy duty. Finally, the repairs to a polyurethane elastomer are much simpler than attempting to repair a conventional elastomer after processing. ${ }^{11}$ 


\subsubsection{Applications of Elastic Polyurethanes}

The applications of castable polyurethanes vary from domestic to industrial and are very tunable depending on the desired system. Most domestic applications of polyurethanes are non-castable foams used for insulation; however, there are still some applications for the domestic use. Boat trailer rollers, engine mounts, and suspensions used in off-road vehicles are all generally made from polyurethanes as well as skateboard wheels and topgrade wheels. In the office, polyurethanes are found on paper transport rollers in printers. The industrial applications of castable polyurethanes are much more prevalent. Industrial wheels from a forklift and rollers in the printing and steel industry utilize different strengths of polyurethane. Polyurethanes have radiation resistance; therefore they can be used in the nuclear industry. Polyurethanes can also be used to create molds for other polyurethane parts so long as a mold release spray is applied.

\subsection{Raw Materials}

\subsubsection{Polyols}

The polyol system chosen can be varied depending on how hard or soft the desired material should be. The polyol portion of the polyurethane backbone is known as the 'soft' segment and is capped with hydroxyl groups. Generally polyols are linear except in specific applications where branching might be necessary. The overall molecular weight of the soft segment is what controls how often the hard segments appear and therefore the stiffness, durability, hardness, and resilience of the final polymer. Therefore, differences in the polyol system chosen greatly affect the polymer. There are two major structural groups into which manufacturers divide polyols. The first group is low molecular weight polyols, and the second group is known as oligo-polyols. ${ }^{3}$ 


\subsubsection{Low MW Polyols}

This first group of polyols are well described in traditional organic chemistry. They are low molecular weight groups having a concrete molecular weight. Most of the molecules that fall in this category are in fact diols like propylene glycol, ethylene glycol, 1,4-butanediol. There are few polyols that fall into this category such as glycerol and triethanolamine. These polyols however are primarily used as chain extenders $(\mathrm{f} \leq 2)$ or as crosslinkers $(f \geq 2)$. The polyurethanes prepared using these polyols have very predictable and controllable properties as the molecular weight of the repeating units are known precisely. ${ }^{6}$

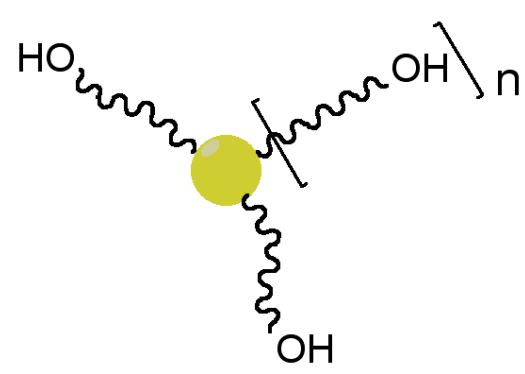

= a chemical organic structure, aliphatic, cycloaliphatic, aromatic, heterocyclic, etc

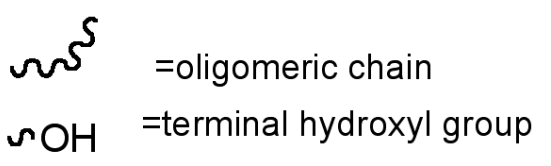

$\mathrm{n}=$ number of chains derived from one hydroxyl group $\mathrm{f}=\mathrm{n}+2=$ functionality (total number of hydroxyl groups $/ \mathrm{mol}$ )

Figure 1.10. The general formula of oligo-polyols used in polyurethanes.

\subsubsection{Oligo-Polyols}

Consequently to the first group of polyols where the MW and functionality are known exactly exist, these oligo-polyols consist of low MW polymers terminated with hydroxyl functionality. Figure $1.10^{3}$ shows a general formula for these oligo-polyols. The molecular weight of the oligo-polyols generally vary between $300-10000 \mathrm{~g} / \mathrm{mol}$ and usually contain 2-8 $\mathrm{OH}$ groups/mol. Although the hydroxyl number of these polymers can vary from two to eight groups/mol, polyols with higher numbers are rarely used. ${ }^{3}$

The hydroxyl number of an oligo-polyol is a very important value that drastically changes the properties of the resulting polyurethane. Defined as the quantitative number 
of available hydroxyl groups for the reaction with isocyanates, it must be determined experimentally through the reaction of the terminal hydroxyl groups with an organic anhydride. The carboxyl groups that result from this reaction are neutralized with an equimolar quantity of potassium hydroxide. ${ }^{7}$ Therefore, the hydroxyl number is calculated using Equation 1:

$$
O H \#=\frac{f 56100}{M_{n}}
$$

where $\mathrm{OH} \#$ is the hydroxyl number of the oligo-polyol in $\mathrm{mg} \mathrm{KOH} / \mathrm{g}$., $f$ is the functionality, or the number of $\mathrm{OH}$ groups $/ \mathrm{mol}$ polyol, $\mathrm{M}_{\mathrm{n}}$ is the number average molecular weight of the polyol, and 56100 is the equivalent weight of $\mathrm{KOH}$ in $\mathrm{mg}$. The step-by-step procedure for hydroxyl number determination using acetic anhydride is outlined in ASTM E222.12

\subsubsection{Tailoring Oligo-Polyol Properties}

A polyol that has low functionality, or 2-3 OH groups/mol and a high MW of 2000-6500 g/mol will lead to an elastic polyurethane. Many factors contribute to the elasticity of the resulting polymer. Firstly, there is a high mobility of the oligo-polyol chains, which allows for the free rotation around the bonds of the main chain end. For this reason, these polymers generally have a low glass transition temperature $(\mathrm{Tg})$. With a glass transition far below room temperature, the elasticity of the polymer chains are in the highly elastic domain, and therefore elasticity is maintained at any temperature above the Tg. When reacted with a diisocyanate, the resulting structure will be a low crosslinked, flexible polyurethane most usually characteristic of a polyurethane foam. Due to the crosslinked nature of the resulting structure, the molecular weight is ill-defined. 
Consequently, if a polyol has high functionality (3-8 OH groups/mol) and a low molecular weight (300-1000 g/mol), it will lead to a highly crosslinked, rigid polyurethane. In this case, if this classification of polyol is reacted with a diisocyanate or polyisocyanate, a very hard, rigid polymer structure is obtained characteristic of the high crosslink density of the resulting polyurethane polymer.

\subsubsection{Polybutadiene Polyols}

Many different types of oligo-polyols are used in polyurethane synthesis. Eighty percent of all PU syntheses actually uses a polyalkylene oxide polyether polyol; however, this study focuses on a different oligo-polyol that is used less prevalently, the polybutadiene polyol. For these polyols, radical polymerization is used in the synthesis of these hydroxyl terminated (HT) macro monomers. When dienes are subjected to radical polymerizations, which are non-stereospecific, several different microstructures are generated in the same chain. For butadiene, 1,2-addition can occur, where only one double bond propagates in the polymerization. It is also likely that 1,4-addition will occur, where both double bonds are propagated through. The 1,4-addition also can

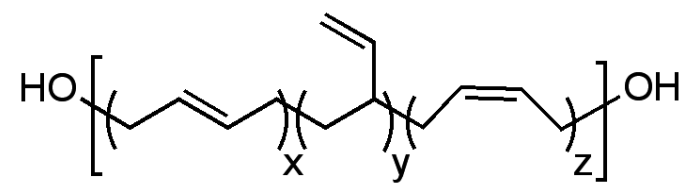

Figure 1.11. A generic structure of a hydroxyterminated polybutadiene is shown where $x, y$, and $\mathrm{z}$ represent the ratios of 1,4-trans, 1,2-, and 1,4-cis addition of the butadiene.

present in cis or trans microstructures. The reaction conditions can be tailored such that differing proportions of 1,2-, 1,4-cis, and 1,4-trans propagation occurs. ${ }^{13}$

This study focuses of three different hydroxyterminated polybutadiene (HTPB) polyols, R45HTLO, Poly bd-LF3, and Krasol LBH-2000, each with differing percentages of each microstructure. The general formula for the HTPB prepolymer is shown in Figure 
1.11 where $\mathrm{x}$ represents the percentage of 1,4-trans addition, $\mathrm{y}$ represents the percentage of 1,2-addition, and $\mathrm{z}$ represents the percentage of 1,4-cis addition. There are special applications for HTPB polyurethanes due to the completely nonpolar soft segments and extraordinary hydrophobicity. HTPB based polyurethanes also have excellent electrical insulation properties perhaps even rivaling silicone elastomers or epoxies. ${ }^{3}$ For all of these reasons, HTPB polyurethanes are primarily used as binders for solid propellants, encapsulating compounds, and high performance hydrolysis resistant and hydrophobic elastomers. ${ }^{3}$

\subsubsection{Diisocyanates/Polyisocyanates}

Diisocyanates are the second component needed in polyurethane synthesis, and are equally as important as the polyols; however where the polyol was responsible for the

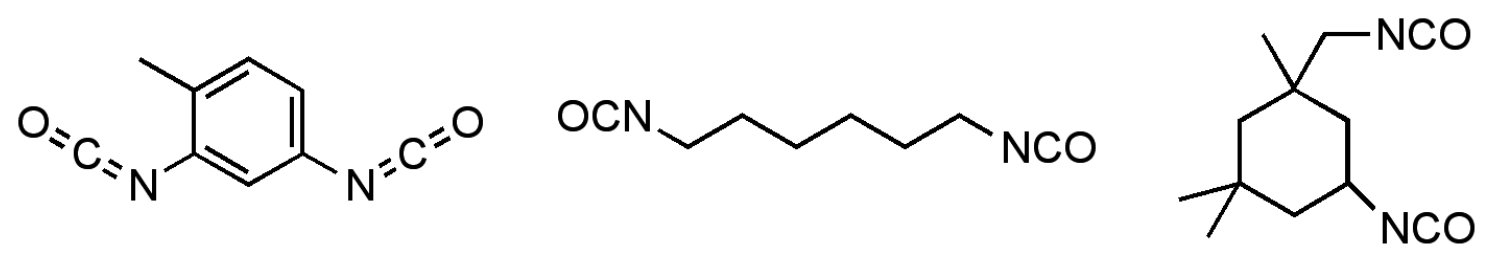

Figure 1.12. Structures of toluene diisocyanate, hexamethylene diisocyanate, and isophorone diisocyanate are shown.

soft segment of the polymer, the di- or triisocyanate groups are responsible for the hard segment of the chain. The structure of the isocyanate is adjusted in order to affect the rate of the reaction versus the physical properties of the end polymer. The reactivities of different isocyanates provide a good way to tailor reaction speed. ${ }^{14}$ For example, toluene diisocyanate (TDI), hexamethylene diisocyanate (HMDI), and isophorone diisocyanate (IPDI) should all have different reactivities because of their root structures. As seen in Figure 1.12, toluene diisocyanate contains two benzyl isocyanates, HMDI has two $1^{\circ}$ isocyanates, and IPDI has one $1^{\circ}$ and one $2^{\circ}$ isocyanate. 


\subsubsection{Formation of Isocyanates}

There are two main pathways in which to synthesize isocyanates. The phosgenation of primary amines is one way, and the manufacture of isocyanates via urea is another. The first method, phosgenation, is the more widely used method; however, there are health risks associated with phosgene. ${ }^{14}$

Polyisocyanates have also been developed in order to increase functionality and provide for better crosslink densities. Although there are many types of polyisocyanates, this study focuses only on Desmodur N 3300A, and Desmodur XP 2410. Desmodur N3300A is an isocyanurate while Desmodur XP 2410 is an iminooxadiazine dione. Both of these isocyanates are obtained by the trimerization of 1,6-hexamethylene diisocyanate or HMDI, and provide a larger NCO equivalent weight, resulting in a higher percentage of $1^{\mathrm{o}}$ isocyanate groups and consequently a faster polymerization once exposed to a polyol.

\subsection{Safety Concerns with Polyurethanes}

The largest drawback to the use of polyurethanes are the safety concerns around them. These safety concerns are not solely related to the polyurethanes themselves, which are actually quite benign, but the hazards associated with the raw materials. Isocyanates are one of the most dangerous chemicals used in large scale applications. Not only are isocyanates hazardous, but the manner in which they are produced also pose potential health risks for the workers.

Isocyanates have become dangerous chemicals due to a few different attributes. Firstly, isocyanates are very reactive, reacting with a very wide range of everyday chemicals, sometimes in vigorous fashion, resulting in the evolution of heat. One specific 
example relates to the rapid reaction of isocyanates with water, as shown in section 1.4.1. ${ }^{14}$ In cases where water is able to contaminate a sealed container or is trapped in a container of isocyanate that is subsequently sealed, the generation of carbon dioxide will result in excess pressure. On the large scale, excess pressure could result in a potentially violent explosion. Another example of their reactivity is in the presence of alkalis like sodium hydroxide and potassium hydroxide. Secondly, diisocyanates used in polyurethane chemistry can cause respiratory problems. This problem does not present very often because the diisocyanates used in PUR synthesis have volatility that is much less than water. They can also be absorbed through the skin, through contact with the eyes, by smoking, and through the mouth by swallowing or by eating contaminated food or drink. ${ }^{14}$ Table 1.1 summarizes the health effects of commercial diisocyanates. ${ }^{14}$ Due to their reactivity with water, isocyanates do not harm the environment. Their major products are ureas, which are inert and insoluble. The possible types of exposure are as vapor, as aerosol, as dust, and as liquid. At elevated temperatures, these exposures become more likely.

Table 1.1 Health effects of Diisocyanates. ${ }^{14}$

\begin{tabular}{|l|l|}
\hline Odor & $\begin{array}{l}\text { Cannot be detected by smell unless in } \\
\text { concentrations well above the occupational } \\
\text { exposure limits }\end{array}$ \\
\hline Respiratory Effects & May cause respiratory effects and asthma \\
\hline Eye Irritation & May be irritant to the eyes \\
\hline Skin Irritation & May cause moderate skin irritation \\
\hline Oral toxicities & Very low toxicities when swallowed \\
\hline
\end{tabular}


Safety should be a primary concern to anyone working with isocyanates;

however, if the proper guidelines are used, such as handling the material while wearing gloves and in the hood, polyurethanes can be synthesized safely and effectively. 


\section{REFERENCES:}

1. Meier-Weshues, U., Polyurethanes: Coatings, Adhesives and sealants. Vincentz Network: Hannover, 2007; p 344.

2. Painter, P. C.; Coleman, M. M., Fundamentals of polymer science : an introductory text. 2nd ed.; Technomic Pub. Co.: Lancaster, Pa., 1997; p xv, 478 p.

3. Ionescu, M., Chemistry and technology of polyols for polyurethanes. 2005, xvi, $586 \mathrm{p}$.

4. Amato, I., Chemist Leo Baekeland. TIME Magazine 1999, 3.

5. Bayer, O., Agnew Chem 1947, 59.

6. Ashida, K., Polyurethane and related foams : chemistry and technology. CRC/Taylor \& Francis: Boca Raton, FL, 2007; p 153 p.

7. Odian, G. G., Principles of polymerization. 4th ed.; Wiley-Interscience: Hoboken, N.J., 2004; p xxiv, 812 p.

8. Gielen, M., Tin chemistry : fundamentals, frontiers, and applications. Wiley: Hoboken, NJ, 2008.

9. Wade, L. G., Organic chemistry. 5th ed.; Prentice Hall: Upper Saddle River, N.J., 2003.

10. Clemitson, I., Castable polyurethane elastomers. CRC Press: Boca Raton, 2008; p $250 \mathrm{p}$.

11. Drobny, J. G., Handbook of thermoplastic elastomers. PDL handbook series 2007, xvii, 404 p.

12. ASTM E222: Standard Test Methods for Hydroxyl Groups Using Acetic Anhydride Acetylation. 2000.

13. Polybd Resins in Urethane Elastomers. Atochem Technical Bulletin 1990.

14. Allport, D. C.; Gilbert, D. S.; Outterside, S. M., MDI and TDI : a safety, health and the environment : a source book and practical guide. J. Wiley: New York, 2003; p $\mathrm{xvi}, 438 \mathrm{p}$. 


\section{Development of Undergraduate Polymer Synthesis Laboratory Experiment}

\subsection{Background}

Since the early 1930s when synthetic polymers were first discovered and synthesized by W. Carothers, they have catapulted into the forefront of the chemical industry. Most everyone can't even look around a room without running across a handful of polymers, and most of the world are oblivious to the components of the materials that impact their everyday lives. Likewise, polyurethane chemistry has been used and developed into a wide variety of applications from furniture foams, to aircraft coatings, and for use in binders for insensitive munitions. ${ }^{1}$ For this reason, it is important for students entering their undergraduate polymer science career to understand the impact that polymer science has on society, and the specific specialty applications of polyurethanes.

Polymer students must also be exposed to the different types of polymer architectures. The most widespread and simple polymeric architecture is a linear chain, where there is a single polymer chain with no branches. Here two primary factors affect the physical properties of the polymer: the length of the chain, and the functional groups along the chain. For example, a polymer chain that contains planar phenyl groups within the backbone will allow for pi-stacking, while a polymer with amine functionality throughout will be susceptible to hydrogen bonding. The longer the chains become, the more likely chain entanglement would be, wherein the overall viscosity of a solution would increase due to the increase of chain interaction. Other polymer architectures include branched, star, comb, brush, dendritic, hyper-branched and crosslinked-gel polymers. The branching of the polymer chains greatly affects the ability of the chains to slide past one-another and their solubility in solution. ${ }^{2}$ 
This experiment focuses on the latter-most chain architecture, the highly-crosslinked gel polymers. Upon synthesis, some of these polymers will become slightly crosslinked, forming elastomers like rubber bands, and some polymers become highly crosslinked, manifested in their flexibility but incredible compressibility and strength. Polyurethane gel elastomers are among the most highly crosslinked of the 'elastomeric' region of polyurethanes. As discussed in the previous chapter, PU elastomers are prepared by the reaction of a polyol with a di or polyisocyanate in the presence of a catalyst like dibutyltin dilaurate (DBTDL). For this laboratory experiment, students will be exposed to the hydroxyterminated polybutadiene class of oligo-polyols and to three different types of isocyanates, hexamethylene diisocyanate (HMDI), isophorone diisocyanate (IPDI), and DESMODUR N3300A which is a trimer of HMDI in a proprietary formulation. Polyurethanes prepared with this architecture are most likely to be used as a protective or cushioning binder, or any application that requires a great deal of compressibility strength and flexibility. ${ }^{1}$

In order for a polyurethane to be classified in the gel architecture, one of the components must have a reactive functionality greater than two. This will ensure that chemical crosslinks can form and that the material will form a gel. If both components have a functionality greater than two, this can increase the reaction speed as well as increase the overall strength of the material by increasing the crosslink density.

This experiment explores using three different polyols, three different isocyanates, different amounts of catalyst, and various stoichiometric ratios to determine a qualitative understanding of the end-use physical properties. The experiment also focuses on introducing chemists, possibly for the first time, to statistical experimental design. It 
becomes increasingly important to be able to show statistically that materials perform to a required standard, or that polymer molecular weights are within a certain range. An incorrect or inaccurate analysis of the material in industry could result in product recall, costing the company a significant amount of money.

The statistical experimental design will utilize a two-way ANOVA technique to explore whether there is statistical evidence to support whether variations in the catalyst amount or variations in diisocyanate type affect the overall cure time of the polyurethane elastomer.

\subsection{Goals}

The goals of this experiment are many. First, the students will understand the nature of polyurethane chemistry, the components of the reaction, and the end use applications of the materials. Students will learn that polyols and polyisocyanates can be tuned and functionalized in different ways to create different materials. Catalyst amount will also be explored to determine the ideal amount of catalyst to maximize cure time and keep cost to a minimum. Stoichiometry will also be varied in order to determine how, and if, imperfect stoichiometric ratios affect the final formulation and physical properties.

\subsection{Statistical Methods}

\subsubsection{Importance of Statistics in Experimental Design}

Statistical analysis is of paramount importance if one wishes to quantify the degree of uncertainty when dealing with chemical properties and physical properties of end-use materials. For example, the microchip processors that are produced today are subjected to multiple analyses before a single lot is allowed to be shipped out to consumers. ${ }^{3}$ Statistics 
are used to ensure that each lot of produced microprocessors is in agreement with the other lots produced.

If an experiment to test for these qualities is not designed properly, it can result in a faulty quality assessment, potentially costing a company anything from a few thousand dollars to a complete product recall. ${ }^{3}$

\subsubsection{Observational Study versus Experimental Study}

In the statistical realm, two generalized areas of analysis exist. The most widespread aspect of statistics relates to observational studies. As defined, an observational study is where a researcher collects information concerning the subjects under study without any interference with the process that is generating the information. ${ }^{3}$ The researcher is a passive observer of the events. On the other hand, for experimental studies the researcher takes an active part in manipulating or specifying certain variables that will be studied and records their effects on the response variables. The largest difference between the two types of studies is in the information that can be concluded by the result. In observational studies, only correlations between variables can be determined. In experimental studies however, since the researcher assigned certain variables to observational units, causation can be determined. This experiment highlights the use of designing an experimental study to build a cause-and-effect relationship between the variables of interest.

\subsubsection{Building an Experimental Study}

As previously described in experimental studies the researcher imposes variables onto the experimental units to conclude some piece of information with a given level or percentage of certainty. A designed experiment is an investigation in which an outline is 
provided to observe, measure, and evaluate groups with respect to a designated response variable. ${ }^{3}$ The two types of variable in an experimental study are controlled variables, called factors, which are selected by the researcher for comparison. The second type of variable is the response variable, which is the measurements or observations that are recorded by the researcher. It is important to note that the researcher has no control over the response variable. From the different factors, the researcher builds treatment levels, which are the individual conditions constructed for the study. The treatment levels are formed by creating a factorial treatment design, insuring that every combination of factors is accounted for in the design. One last bit of statistics that must be explained is the experimental unit. This is the entity to which a given treatment level is randomly assigned.

For example, if one wanted to study the maximum weight gain for certain shrimp, it would be designed thusly. Three water temperatures $\left(20^{\circ} \mathrm{C}, 30^{\circ} \mathrm{C}\right.$, and $\left.35^{\circ} \mathrm{C}\right)$ and three water salinity levels $(10 \%, 20 \%$, and $30 \%)$ are assigned to various pools containing between 100 and 300 shrimp each. In a factorial treatment design, there would be 9 treatment levels, each randomly assigned to a different pool. The factors of this study would be temperature and water salinity level, the experimental unit would be one pool, and the response variable would be the weight of each shrimp in the pool. It is also important that there is replication for each experimental unit. For the example above, replication of each experimental unit would mean that there was at least one other pool that was assigned the same treatment combination. All of these factors are important for a researcher to consider when designing an experiment, for forgetting even one could result 
in a study that no conclusions can be formed from which would be a large waste of time, money and resources. ${ }^{3}$

\subsubsection{Two Way Analysis of Variance}

The type of experimental study that is most applicable to this study is a general linear model where there is one dependent and one independent variable. However, if two dependent variables, or factors, exist it is important for a collegiate or industrial chemist to understand how to proceed. A two- way analysis of variance (2-way ANOVA) technique was developed in order to compare multiple categorical or numerical factors against a numerical response variable. ${ }^{3}$ This type of analysis will be a powerful tool for students entering the real world to grasp. As for any statistical study, there are certain assumptions that must be made to be able to analyze the data. In the case of a two-way ANOVA, the data collected must have equal variances. This can be checked using Levene's test for equal variances and is usually tested using a confidence level $(\alpha)$ of 0.05. This value corresponds to the maximum percentage of error that is permitted in the analysis. The statistical data is presented with a certain confidence, and an $\alpha=0.05$ means the result of the study is no less than $95 \%$ conclusive; however, no data can be $100 \%$ conclusive, there is always an element of uncertainty present. ANOVA results include two plots by default, a Main Effects plot, showing whether there is a statistically significant difference between the values in each factor, and the Interaction plot, showing whether there is interaction present between the factors. For the main effects plot, diagonal lines that cross the mean are usually indicative of the presence of a main effect. On the other hand, two factors are said to 'interact' if the lines of the interaction plot are non-parallel. The Minitab output will confirm the visual findings with p-values. When a 
p-value $<\alpha$, the data is said to be statistically significant; however, if $\mathrm{p}>\alpha$ it is

concluded that the data points in the study are not significantly different from each other. ${ }^{3}$

2.4. Experimental Methods and Materials

2.4.1. Raw Materials

Three hydroxyterminated polybutadiene (HTPB) oligo-polyols, tradenames R45HTLO from Sartomer, KRASOL LBH 2000 from Sartomer, and Poly bd LF-3 from Sartomer were used as received from the Cal Poly Polymer and Coatings Program. Isophorone diisocyanate (IPDI) was used as received from Aldrich. Hexamethylene diisocyanate (HMDI) was used as received from ACROS. DESMODUR N3300A was used as received from Bayer. The catalyst, dibutyltin dilaurate (DBTDL) was used as received from Aldrich. A Thinky ARE-100 mixer was used to ensure thorough, gyroscopic mixing. The counterbalance in the mixer was set before each use. All other materials and solvents were readily available from the Chemistry Stockroom. Minitab 16.1.0, licensed through Cal Poly was used for all statistical analysis. Table 1 shows properties of each of the reagents including molecular weight and functionality. It should be noted that since the functionalities of Krasol LBH 2000 and Poly bd LF-3 are 2 and 1.98, respectively, they must be paired with DESMODUR N3300 A to form a gel matrix as DESMODUR N3300A is the only curing agent with a functionality greater than two.

Table 2.1 Important Properties of Raw Materials ${ }^{4}$

\begin{tabular}{ccc}
\hline Component & $\mathrm{M}_{\mathrm{n}}(\mathrm{g} / \mathrm{mol})$ & Functionality \\
\hline R45HTLO & 2800 & 2.5 \\
Krasol LBH 2000 & 2100 & 2 \\
Poly bd LF-3 & 2000 & 1.98 \\
HMDI & 222 & 2 \\
IPDI & 168 & 2 \\
DESMODUR N3300A & $\sim 504$ & $\sim 2.52$ \\
\hline
\end{tabular}




\subsubsection{General Experimental Scheme for HTPB Elastomers}

In a disposable weigh cup, HTPB prepolymer (10 g) was added along with DBTDL. DBTDL was added drop-wise via Pasteur pipet. The contents were premixed for 15 seconds using a Thinky ARE-100 Mixer. Multifunctional isocyanate was added, and the contents were immediately mixed for 30 seconds. Values of each component vary depending on the experiments performed.

\subsubsection{Effect of Catalyst Concentration on Cure Time}

R45HTLO prepolymer (10 g, $3.57 \mathrm{mmol})$ was added to four different disposable weigh cups followed by catalyst DBTDL (0 drops, 10 drops, 60 drops, or 120 drops), ensuring each cup received differing amounts of catalyst. These components were premixed for 15 seconds with the Thinky ARE-100 mixer to allow for complete incorporation of the catalyst into the polyol matrix. IPDI $(0.93 \mathrm{~mL}, 4.46 \mathrm{mmol})$ was added to the cup via graduated syringe and the cup was immediately mixed for 30 seconds. Once mixed, a wooden tongue depressor was used to assign a viscosity value based on a 1-10 scale, where 1 is a liquid like water, 5 is a liquid like honey, and 10 is a solid. Viscosity estimates were made at $0,5,15,30$, and 60 min.

\subsubsection{Effect of the Crosslinking Agent on Cure Time}

R45HTLO prepolymer (10 g, $3.57 \mathrm{mmol})$ was added to three different disposable weigh cups followed by the ideal amount of DBTDL (60 drops) as determined by study 2.4.3. The contents were premixed using the Thinky ARE-100 mixer. To each cup a different isocyanate was added: one with HMDI (.72 mL, $4.46 \mathrm{mmol})$, one with IPDI (0.93 mL, $4.46 \mathrm{mmol})$, and one with DESMODUR N-3300A (1.78 g, $3.53 \mathrm{mmol})$. The 
cup was immediately mixed for 30 seconds. After mixing for 30 seconds, cure time data was collected along with any other observations.

\subsubsection{Effect of the Structure of the Prepolymer}

To each of three disposable weigh cups, a different hydroxyterminated polybutadiene prepolymer was added. R45HTLO (10 g, $3.57 \mathrm{mmol})$ was combined with DBTDL (1 drop) and premixed for 15 seconds. HMDI (0.72 $\mathrm{mL}, 4.46 \mathrm{mmol})$ was added and the contents were mixed for 30 seconds. This process was repeated with Krasol LBH-2000 (10 g, $4.76 \mathrm{mmol})$ as the HTPB and DESMODUR N-3300A (1.90 g, $3.77 \mathrm{mmol})$ as the curing agent. The process was repeated with Polybd LF-3 (10 g, $5.00 \mathrm{mmol})$ and DESMODUR N-3300A ( $1.98 \mathrm{~g}, 3.93 \mathrm{mmol}$ ) as prepolymers, all using a 1:1 ratio of isocyanate to alcohol. Samples were placed in the oven at $60{ }^{\circ} \mathrm{C}$ and allowed to cure for 48 hours. Samples were removed from the oven and qualitative observations were recorded regarding the physical appearance and their pliability.

\subsubsection{Effect of Crosslinking Density}

R45HTLO prepolymer (12 g, $4.28 \mathrm{mmol})$ and DBTDL (10 drops) were added to three different disposable weigh cups. Three different gels were made by adjusting the ratio of R45HTLO to IPDI. IPDI (1.12 mL, $5.35 \mathrm{mmol})$ was added to the $1: 1 \mathrm{cup}$, IPDI $(1.01 \mathrm{~mL}$, $4.83 \mathrm{mmol})$ was added to the $0.90: 1 \mathrm{cup}$, and IPDI $(0.84 \mathrm{~mL}, 4.02 \mathrm{mmol})$ was added to the $0.75: 1$ cup. Once fully mixed for 30 seconds, the mixtures were transferred via pipette into prepared silicone molds and cured at $60{ }^{\circ} \mathrm{C}$ until the following lab period. The samples were removed from the molds and cut into identical pieces and weighed. Each sample was submerged in a constant amount (by wt) of various solvents (acetone, THF, and methanol) in a sealed container to prevent mass loss due to volatility. The samples 
were carefully removed and weighed after $5,10,20,40,60,90$, and 120 minutes. The samples were submerged for 48 hours to get a final weight.

\subsubsection{Statistical Randomized Block Design Exploring Catalyst Amount and}

Isocyanate Type

A statistical experiment was designed to determine the best combination of catalyst amount and curing agent to produce the fastest and least costly polymer possible. A TwoWay ANOVA was used to determine whether there was a statistically significant difference in the amount of time it takes for a polyurethane gel to cure depending on the amount of catalyst and the type of curing agent.

The treatment structure was catalyst amount at 4 levels (5 drops, 20 drops, 35 drops, and 60 drops) and curing agent at 2 levels (HMDI, and IPDI) making 8 different treatment combinations, shown in Table 2.2.

Table 2.2 Treatment Combinations for Experimental Study

\begin{tabular}{ccc}
\hline $\begin{array}{c}\text { Treatment } \\
\text { Combination }\end{array}$ & $\begin{array}{c}\text { Catalyst Amount } \\
\text { (in drops) }\end{array}$ & Curing Agent \\
\hline 4 x A1 & 5 & HMDI \\
$4 \times$ A2 & 20 & HMDI \\
$4 \times$ A3 & 35 & HMDI \\
$4 \times$ A4 & 60 & HMDI \\
$4 \times$ B1 & 5 & IPDI \\
$4 \times$ B2 & 20 & IPDI \\
$4 \times$ B3 & 35 & IPDI \\
4 x 4 & 60 & IPDI \\
\hline \hline
\end{tabular}

The response variable was cure time (in seconds), the experimental unit was a $5 \mathrm{~g}$ HTPB urethane elastomer sample, and the design structure is a completely randomized design (CRD). In order to ensure a CRD, Minitab was used to randomize the order which the cups were tested. The same operator performed all of the tests to minimize deviations 
in the study. A four-fold replication for each treatment combination was utilized producing 32 total samples.

R45HTLO (5 g, $1.79 \mathrm{mmol})$ was added to 32 disposable weigh cups. DBTDL was added depending on the treatment combination assigned to the cup as depicted in Table 2.2. Each cup was premixed for 15 seconds. Curing agent was added to one cup at a time depending on the treatment combination: HMDI (0.359 mL, $2.23 \mathrm{mmol})$, or IPDI (.467 $\mathrm{mL}, 2.23 \mathrm{mmol})$. Exactly two seconds after the addition of the curing agent, the cup was mixed for 30 seconds. The timer was started once mixing was complete. The cure time of the samples were determined based on the operators perception of cured, which was defined as follows. A tongue depressor was touched lightly to the surface of the curing elastomer in the cup. If the depressor penetrated the surface, the elastomer was not yet cured. To minimize variability, the same operator was used for all tests, and the tongue depressor was touched to different area of the surface each measurement. Figure 2.1 shows images of the experimental setup with the Thinky ARE-100 as well as a zoomed in picture of an experimental unit, the $5 \mathrm{~g}$ sample of polyurethane elastomer.
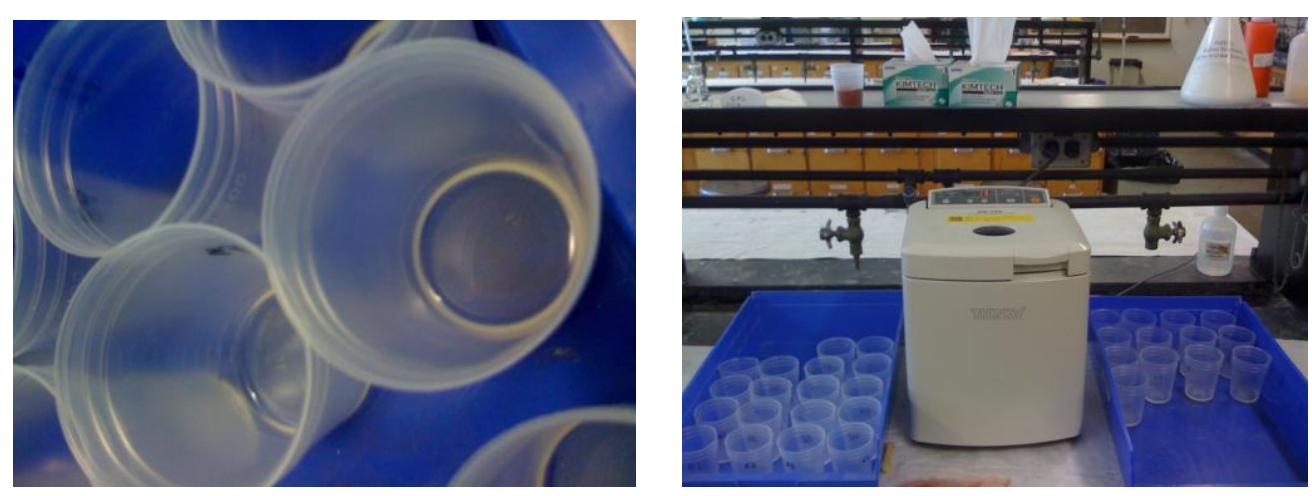

Figure 2.1. The experimental setup is shown (right) along with a zoomed in picture of a curing polyurethane elastomer (left). 


\subsection{Results and Discussion}

\subsubsection{Effect of Catalyst Concentration on Cure time}

Using a 1:1 ratio of isocyanate to alcohol, R45HTLO prepolymer and IPDI were combined with varying amounts of catalyst. The four formulations were assigned qualitative viscosity values, and the data is summarized in Figure 2.2. As shown in 2.2, the formulation without catalyst did not increase in viscosity throughout the experiment; however once catalyst was present, the reaction did cure at different speeds. This can be attributed to the activation energy (Ea) of the of the polyurethane reaction. Without the presence of the catalyst, the Ea is too high resulting in no cure. Both the sample with 60 drops of catalyst and 120 drops of catalyst cured at relatively the same rate; therefore it would not be economical to use 120 drops of catalyst over 60 drops. For future studies, it is advisable to use only 60 drops of catalyst for a $10 \mathrm{~g}$ sample to maximize both value and

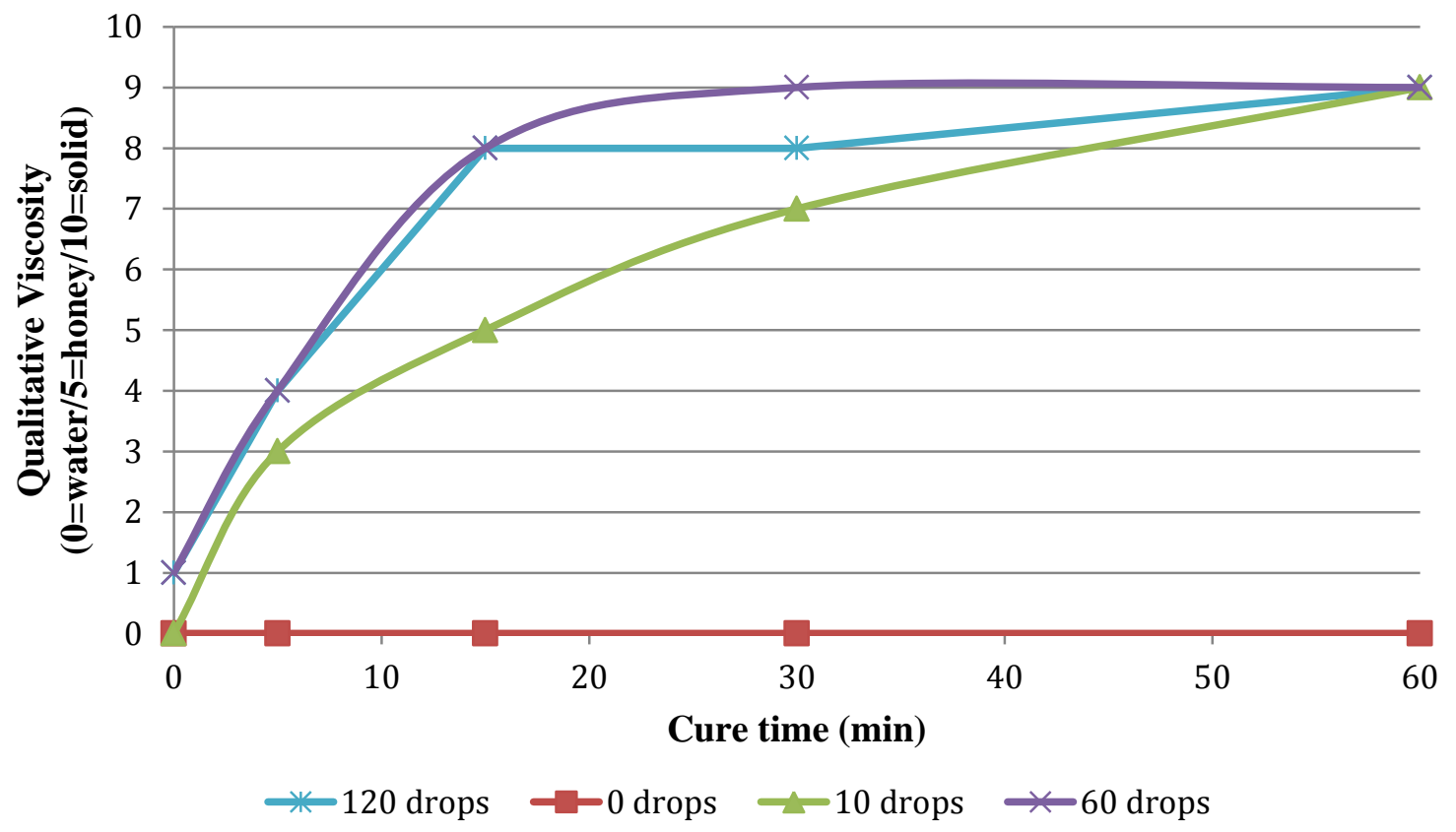

Figure 2.2. Qualitative viscosity, as determined by a tongue depressor, versus cure time (min). 
speed. Raw data is available in Appendix A.

\subsubsection{Effect of the Crosslinking Agent on Cure Time}

Three samples were prepared with three different multifunctional isocyanate crosslinking agents, IPDI, HMDI, and DESMODUR N3300A. The cure times for each sample are shown in Table 2.3 and are around 45, 10, and 2 minutes for IPDI, HMDI, and DESMODUR N3300A respectively.

Table 2.3. Cure Times of Different Crosslinking Agents

\begin{tabular}{cccc} 
& IPDI & HMDI & DESMODUR N3300A \\
\hline Cure time (min) & 45 & 10 & 2 \\
\hline
\end{tabular}

This can be attributed to the different molecular structures of the di- and multifunctional isocyanates. Isophorone diisocyanate and hexamethylene diisocyanate both have functionalities of two; however, the structures of the compounds and the accessibility of the reactive groups differ. IPDI has one primary isocyanate and one secondary isocyanate resulting in a slower reaction speed than HMDI, which has two primary isocyanates. HMDI also has more linear flexibility and, therefore, the $\mathrm{NCO}$ groups can find the $\mathrm{OH}$ groups on the polyol more readily. DESMODUR N3300A is a trimer of HMDI and has a
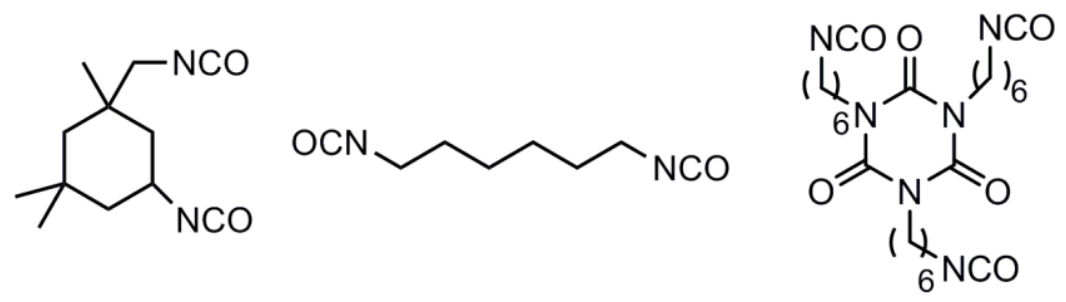

Figure 2.3. The structures of HMDI, IPDI, and generic DESMODUR. calculated functionality of 2.52. Based on the generic structure of DESMODUR shown in Figure 2.3, all of the reactive isocyanates are primary, resulting in a much faster reaction speed. The exact composition of DESMODUR N3300A is not known. The 
multifunctionality results in a curing time of only two minutes, which is very fast and significantly exothermic when compared to the other two elastomers. Raw data is available in Appendix A.

2.5.3. Effect of the Structure of the Prepolymer

Continuing to use a 1:1 ratio of isocyanate to alcohol, three samples were prepared: R45HTLO and HMDI, Krasol LBH2000 and DESMODUR N3300A, and Poly bd LF-3 with DESMODUR N3300A. After curing at $60{ }^{\circ} \mathrm{C}$ for 48 hours, the samples were analyzed. Characterization of the sample was performed in various qualitative ways that included the amount of $\mathrm{CO}_{2}$ produced, the color, the texture, the flexibility, and the hardness. Table 2.4 shows each formulation coupled with the observations made.

Table 2.4. Observations of Polyurethanes with Varying Prepolymer

\begin{tabular}{ccc} 
HTPB & Isocyanate & Observations \\
\hline R45HTLO & HMDI & $\begin{array}{c}\text { Orange, transparent, slightly } \\
\text { rigid, flexible, tore easily, } \\
\text { bubbles }\end{array}$ \\
\hline Krasol LBH 2000 & DESMODUR N3300A & $\begin{array}{c}\text { White / semi-transparent, very } \\
\text { flexible, elastomeric, many } \\
\text { bubbles }\end{array}$ \\
\hline Poly bd LF-3 & DESMODUR N3300A & $\begin{array}{c}\text { Yellow, opaque, very rigid, stiff, } \\
\text { small bubbles }\end{array}$ \\
\hline
\end{tabular}

When isocyanates and polyurethanes are exposed to air, water in the atmosphere destroys the unreacted isocyanates making carbamic acid. Carbamic acid will decompose via the Hofmann rearrangement to give primary amines and carbon dioxide gas, causing bubbles to form in the samples. The coloration can be attributed to the presence of the amines as a result of the above decomposition. Amines can react with the unreacted isocyanate to 
form polyureas as well as produce the yellow color. The more amine that was produced and reacted, the more yellow the samples were. Since the sample composed of R45HTLO and HMDI took the longest to cure, due to the functionality of the HMDI as compared to the DESMODUR N3300A, it had the most oxidation of the amines and therefore produced the most discoloration. Although the Thinky mixer was used to minimize bubble formation when mixing, there was still some air or water in the samples causing the production of carbon dioxide.

Poly bd LF-3 was determined to be the toughest, or most rigid, of the elastomers. This is to be expected because the HTPB prepolymer has the highest ratio of 1,2 addition fragments as compared to R45HTLO and Krasol LBH2000. The conformation of the 1,2addition of butadiene results in a shorter polymer chain length resulting in a less flexible material. Due to the insolubility of all network elastomers, the most efficient way to perform mechanical testing on the materials would be by using strength/toughness tests such as elongation and compression using an Instron. Unfortunately, those instruments were not practical for students to use in the timeframe of this experiment.

\subsubsection{Effect of Crosslinking Density}

R45HTLO and IPDI were used to make three different formulations based upon various ratios of isocyanate to alcohol $(1: 1, .0 .90: 1$, and $0.75: 1)$. After curing at $60{ }^{\circ} \mathrm{C}$ for 48 hours, the samples were cut into three equivalent pieces, weighed, and submerged in three solvents: acetone, methanol, and tetrahydrofuran (THF). The samples were weighed at $0,5,10,20,40,60,90$, and 120 minutes. The masses are shown in Table 2.5 at each increment. 
Table 2.5 Swelling Results

\begin{tabular}{c|ccc|cccc|ccc}
\hline & \multicolumn{3}{c}{$\mathbf{0 . 7 5 : 1 . 0}$} & \multicolumn{4}{c}{$\mathbf{0 . 9 0 : 1 . 0}$} & \multicolumn{3}{c}{$\mathbf{1 . 0 : 1 . 0}$} \\
\cline { 2 - 10 } Minutes & Acetone & THF & MeOH & Acetone & THF & MeOH & Acetone & THF & MeOH \\
\cline { 2 - 10 } $\mathbf{0}$ & $\mathbf{( g )}$ & $\mathbf{( g )}$ & $\mathbf{( g )}$ & $\mathbf{( g )}$ & $\mathbf{( g )}$ & $\mathbf{( g )}$ & $\mathbf{( g )}$ & $\mathbf{( g )}$ & $\mathbf{( g )}$ \\
\hline \hline $\mathbf{5}$ & 4.24 & 4.43 & 4.21 & 4.70 & 4.32 & 4.10 & 4.44 & 4.62 & 3.86 \\
$\mathbf{1 0}$ & 4.29 & 5.02 & 4.22 & 4.78 & 4.87 & 4.13 & 4.86 & 5.31 & 3.88 \\
$\mathbf{2 0}$ & 4.41 & 6.73 & 4.25 & 4.82 & 5.18 & 4.15 & 4.90 & 5.73 & 3.90 \\
$\mathbf{4 0}$ & 4.44 & 7.67 & 4.28 & 4.92 & 6.50 & 4.16 & 5.03 & 6.64 & 3.91 \\
$\mathbf{6 0}$ & 4.52 & 8.67 & 4.31 & 4.97 & 7.20 & 4.17 & 5.09 & 7.13 & 3.92 \\
$\mathbf{9 0}$ & 4.59 & 10.16 & 4.31 & 5.19 & 8.25 & 4.18 & 5.15 & 8.36 & 3.92 \\
$\mathbf{1 2 0}$ & 4.63 & 11.65 & 4.33 & 5.68 & 9.49 & 4.18 & 5.22 & 9.10 & 3.92 \\
\hline$\Delta$ & 0.39 & 7.22 & 0.11 & 0.98 & 5.18 & 0.08 & 0.78 & 4.48 & 0.05 \\
\hline
\end{tabular}

It can be seen through Table 2.5 that each solvent did swell the elastomer; however, it appears that THF was the most successful in swelling the elastomer regardless of the stoichiometric ratio. The largest swelling occurred with the $0.75: 1.0$ sample with THF as the solvent. The difference of $7.22 \mathrm{~g}$ can be attributed to the lesser crosslink density of the $0.75: 1.0$ sample. When the stoichiometry of the reagents deviated far from $1: 1$, it greatly affects the conversion of a step growth polymerization. When combined with the formation of a urethane elastomer, the poor conversion manifests in the lower crosslink density. Samples with higher crosslink density do not allow for as much permeability into the network matrix, and therefore absorb less solvent. THF caused the most swelling when compared to methanol and acetone because it is the most nonpolar solvent used. On the other hand, methanol is very polar and protic which is why the gels swelled the least. There was less ability for the methanol to penetrate the matrix. Figure 2.4 shows a graphical representation of the swelling for each gel in THF as the solvent. There is some 


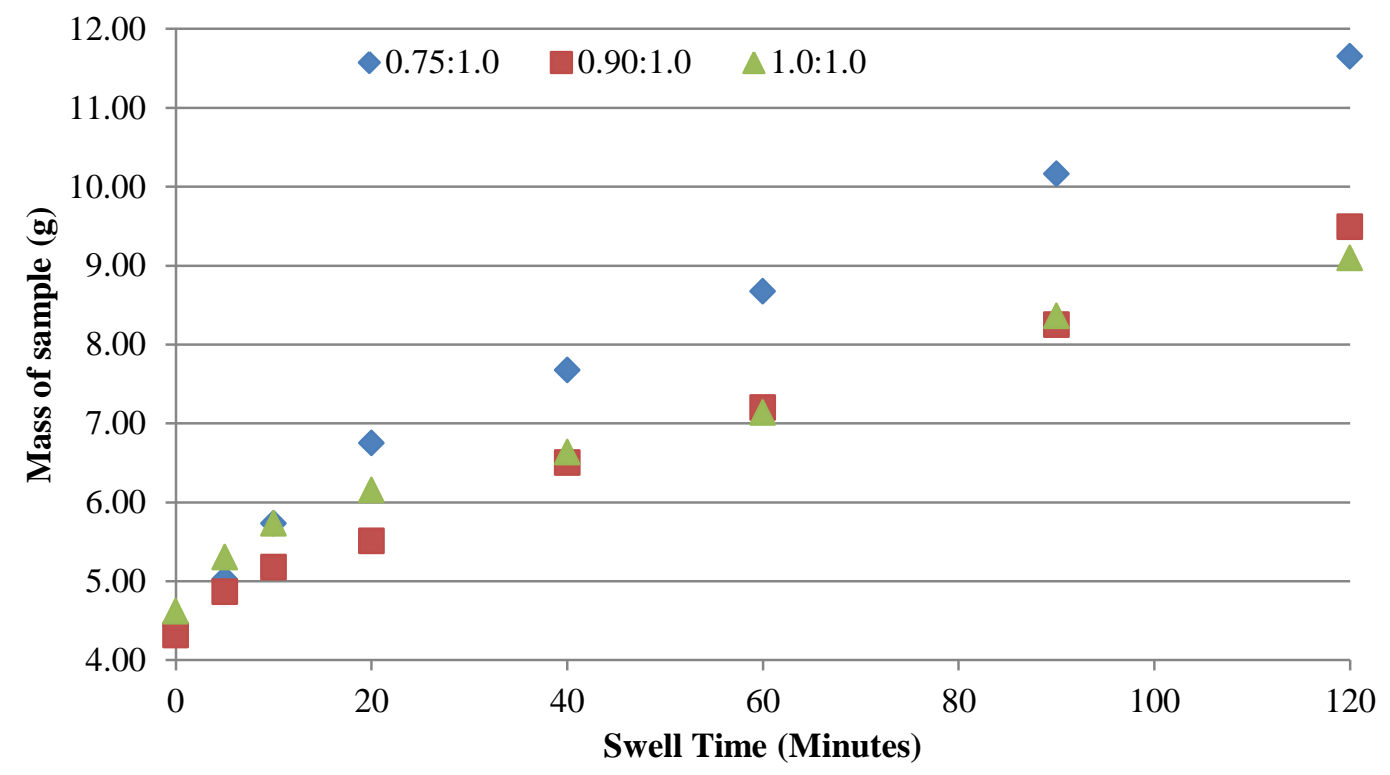

Figure 2.4. The swelling trends for the three formulations in THF over 120 minutes.

variability between the $.90: 1.0$ sample and the $1: 1$ sample during the first hour of swelling; however after 120 minutes, the swelling equilibrated to correctly match the crosslink densities of the three gels. The raw data is available in Appendix A.

\subsubsection{Two-way ANOVA Results}

The statistical data was collected on the eight treatment combinations utilizing fourfold replication and analyzed using Minitab at $\alpha=0.05$, Tukey Comparisons, independent samples, and independent order randomization. The assumptions made to perform the statistical analysis were: using Levene's test equal variances ( $p=.086)$. Even though $\mathrm{p}>0.05$, which suggests there is evidence to support that the variances may not be equal, the residual plots were fairly normal and non-skewed. Upon these considerations, the analysis was continued with caution. The complete output is available in Appendix B including residual plots and assumption tests. 
Figure 2.5 shows a main effects plot for cure time. Significant crossing of the mean value usually denotes that a main effect does exist in a given value. For variations in catalyst amount, a p-value $<0.001$ confirms that there is a catalyst main effect. This means that with $95 \%$ certainty, changing the amount of catalyst will change the cure time. Further analysis of the variations in the catalyst amount showed that there was not a significant difference between adding 35 drops of catalyst versus 50 drops of catalyst.

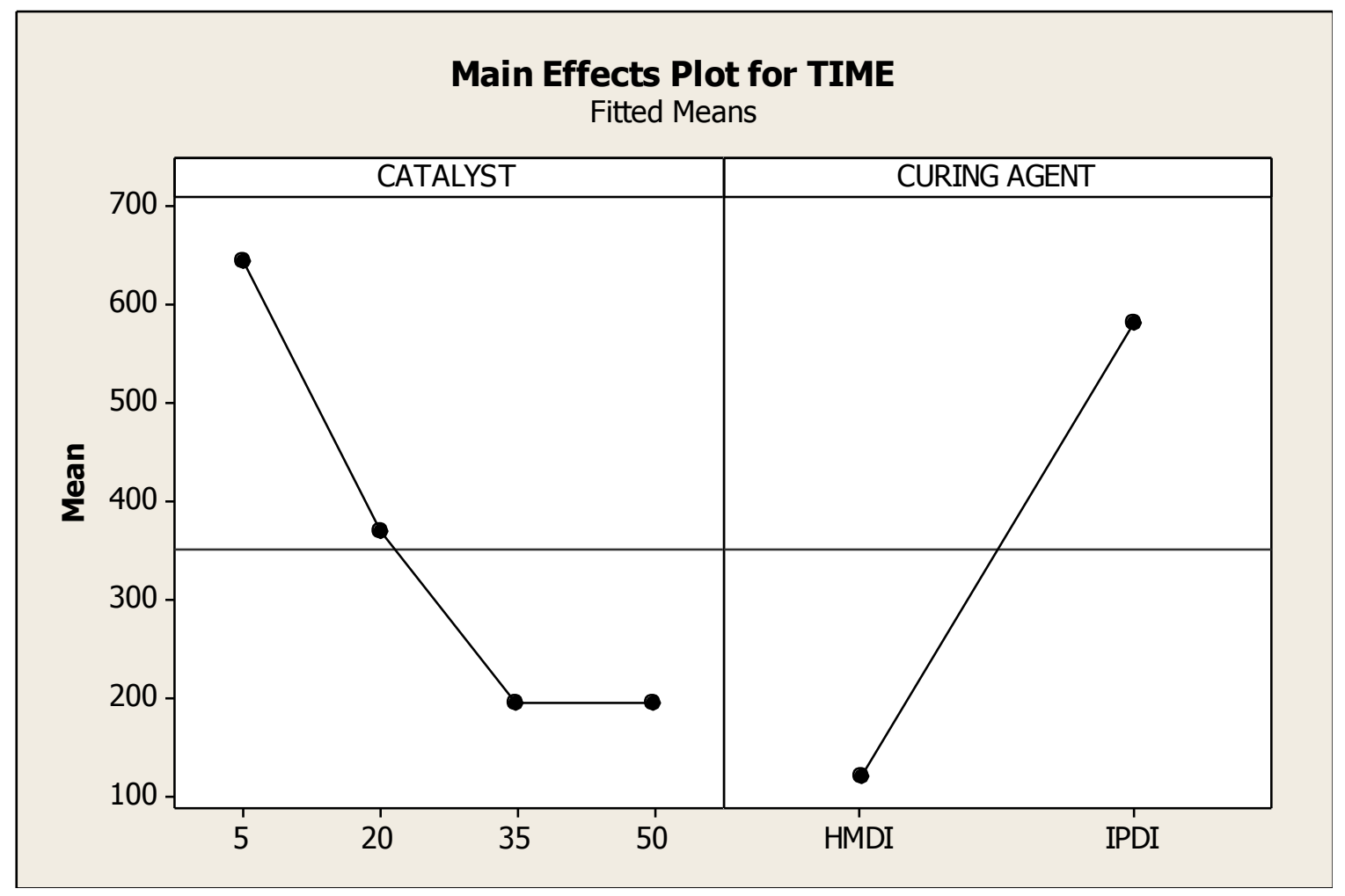

Figure 2.5. The main effects plot for cure time with both catalyst treatment and curing agent treatment are shown.

There is also statistical evidence, $\mathrm{p}<0.001$, to support that the type of curing agent affects the cure time, meaning IPDI and HMDI cure the polyurethane at different rates. This is supported by the structures of the diisocyanates, wherein IPDI reacts more slowly due to steric hindrance around the secondary isocyanate. 
Now that it has been established that both catalyst amount and curing agent type play roles in determining the cure time of the polyurethane, it is important to understand, using an interactions plot, if the two factors interact with each other. Figure 2.6 shows the interactions plot. Interactions are said to be present in these plots of the lines comparing the factors are not parallel. Since neither set of these lines are parallel, there is significant statistical evidence suggesting that the catalyst and the curing time interact with each other to affect the cure time.

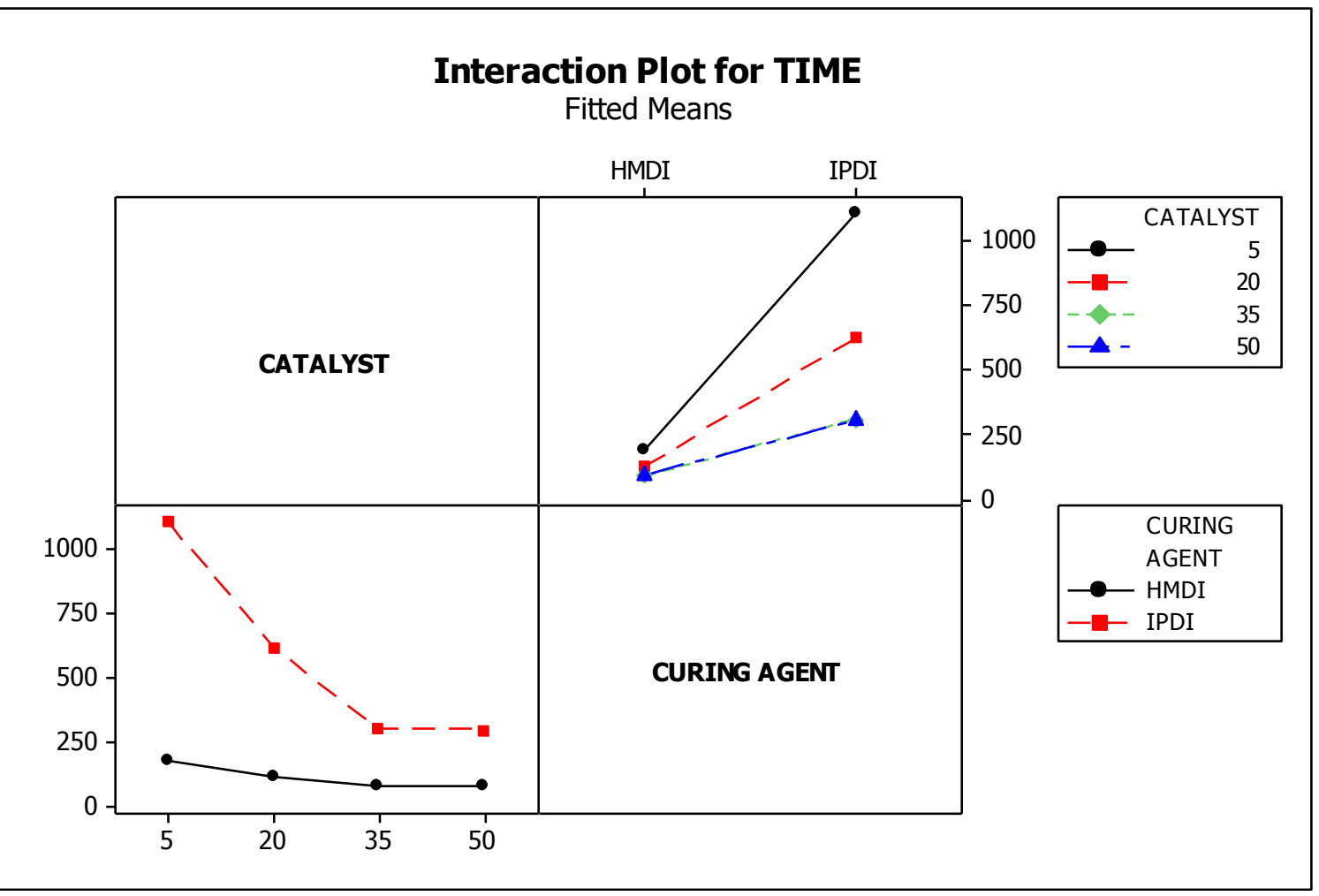

Figure 2.6. The interactions plot for catalyst and curing agent with respect to cure time is shown.

The data collected by the statistical experiment is in agreement with the trends seen in the first parts of the lab; therefore students are able to connect the importance of statistics with everyday laboratory activities. 


\subsection{Hazards}

Care should be exercised when isocyanates are used in the laboratory. Although the volatility is much lower than water, isocyanates are very reactive and toxic. Isocyanate waste should be disposed of in a properly labeled container. Students should wear gloves and only handle the isocyanate in the hood in case of a spill.

\subsection{Conclusion}

Polyurethane elastomer synthesis provides a straightforward opportunity for undergraduate polymer or chemistry students to begin experimenting and understanding the nature of some gel/network polymer systems, which are utilized in countless products and industries. Students are also re-exposed to the concepts of steric hindrance related to reaction rate. Understanding the differences in curing agents and learning how to calculate functionalities is very important for all network polymers, and understanding how the composition of a polymer backbone can affect the mechanical properties of an elastomer cannot be underemphasized. Lastly, crosslink density plays an important role in understanding permeability of polymer systems and the elasticity of various networks.

The incorporation of the statistical analysis also gives the students an opportunity to be exposed to statistical experimental design without dedicating a whole ten week class to the subject. This statistical study should give students enough of a background to know when a statistically designed experiment is and isn't necessary. It will also familiarize students with Minitab, a useful program in statistical analysis. Seldom does one laboratory experiment touch on such a variety of different subjects, especially in just two three hour lab periods. 


\section{REFERENCES}

1. Ionescu, M., Chemistry and technology of polyols for polyurethanes. 2005, xvi, $586 \mathrm{p}$.

2. Painter, P. C.; Coleman, M. M., Fundamentals of polymer science : an introductory text. 2nd ed.; Technomic Pub. Co.: Lancaster, Pa., 1997; p xv, 478 p.

3. Ott, L.; Longnecker, M., An introduction to statistical methods and data analysis. 6th ed.; Brooks/Cole Cengage Learning: Australia ; United States, 2010; p xv, 1273 p.

4. Costanzo, P. J., Lab Manual CHEM 448/548. California Polytechnic State University: San Luis Obispo, CA, 2009. 
3. Design and Development of a Polyurethane Torso Brace for Patients Suffering from Spinal Muscular Atrophy

\subsection{Spinal Muscular Atrophy}

Spinal muscular atrophy (SMA) was unknown until around 1970; however, until about 15 years ago, not much was understood about the disorder. The disorder is fairly rare, occurring in only 1 of every 25,000 subjects. ${ }^{1}$ Proximal spinal muscular atrophy (SMA) is the most common type of SMA, and is an autosomal recessive disorder caused by the death of the motor neurons in the spinal cord. The death of these neurons is a result of the deletion and/or mutation of the survival motor neuron (SMN) gene. ${ }^{1}$ The disorder can also be caused by the mutation of other genes; however SMN is most common. ${ }^{2}$

The clinical spectrum of SMA ranges anywhere from early infant death to normal adult life with only mild weakness. Classifications of SMA are assigned not given the severity of the disorder but by the time of onset. The types of SMA: Type 1, Type 2, Type 3, and Type 4, differ greatly in the quality of life for the subject of the disorder. Table 3.1 outlines the differences in the types.

Table 3.1. Descriptions of SMA types

\begin{tabular}{|c|c|c|c|}
\hline Group & Eponym & Onset age & Description \\
\hline $\begin{array}{l}\text { Type 1: } \\
\text { Infantile }\end{array}$ & $\begin{array}{l}\text { Werdnig- } \\
\text { Hoffmann disease }\end{array}$ & 0-6 months & $\begin{array}{c}\text { Severe infantile SMA, manifests at a young age, death } \\
\text { eminent without respiratory support, pneumonia causes } \\
\text { death }\end{array}$ \\
\hline $\begin{array}{c}\text { Type 2: } \\
\text { Intermediate }\end{array}$ & & $\begin{array}{c}7-18 \\
\text { months }\end{array}$ & $\begin{array}{c}\text { Children can never stand nor walk, sitting position } \\
\text { maintained, grow weaker over time }\end{array}$ \\
\hline $\begin{array}{l}\text { Type 3: } \\
\text { Juvenile }\end{array}$ & $\begin{array}{c}\text { Kugelberg- } \\
\text { Welander disease }\end{array}$ & $>18$ months & $\begin{array}{l}\text { Persons could walk at some point, may lose motor ability } \\
\text { later, }\end{array}$ \\
\hline $\begin{array}{l}\text { Type } 4: \\
\text { adult }\end{array}$ & & $>18$ years & Mild back weakness \\
\hline
\end{tabular}

Most children that suffer from Type 1 SMA, or Werdnig, Hoffmann disease, do not live past one year old. The severe lack of development of the muscles around the spinal 
cord near the vital organs causes failure of most vital systems. Usually the respiratory system is the first to be affected because the lungs can never fully develop without a defined and supported rib cage. In this case, the child will die of pneumonia due to the inability to expel built-up fluid from inside the lungs. ${ }^{2-3}$ Patients with Type 2 are able to sit upright for at least part of their life, but the ability to walk is never achieved. Onset of Type 2 ranges from 6 months to 18 months, and the survivability of these cases is much increased, especially if diagnosed early on. Type 3 can develop any time between 18 months and 18 years and therefore has a wide range of pronunciations. Some subjects never lose the ability to walk, while some experience degeneration as sever as a Type 2 case. Finally, adult onset SMA is the least severe. Most adults that present with the mutation or degradation of the SMN gene simply experience back weakness and back pain. $^{2}$

The cause of SMA was not well known until the mid nineties, when is was discovered that chromosome 5 contains the SMN gene. This chromosome has a large duplication, and a large sequence that contains several genes occurs twice in two adjacent segments of DNA. The two copies of the SMN gene, known as SMN1 and SMN2 differ only by a few base pairs; however it is the SMN1 that experiences a silent mutation at the splice junction of intron 6 to exon 7. The mutation results in a portion of the transcripts being inappropriately spliced into a form excluding exon 7 . This shorter mRNA results in a shorter SMN protein, causing rapid degeneration of the protein. ${ }^{1-3}$ The severity of the SMA is a direct result to how well the remaining SMN2 genes make up for the loss of SMN $1 .{ }^{3}$ 
Regardless of the severity, a child that is affected by SMA will experience quite a different quality of life than normal children. The disorder is occasionally coupled with other mental disabilities; however, some subjects also have an increased intellect comparative to a mild form of autism. ${ }^{1}$

\subsection{Current technology}

\subsection{1. $\quad$ Full torso braces}

Most children that suffer from SMA face a severe physical disability as a result of the weakness of the spine. If not properly supported, the child could easily damage their spinal cord, most likely resulting in death. For this reason, SMA subjects normally wear a full-torso brace at all times during the day. However, due to the small proportion of the population that suffers from SMA, an ideal brace technology has never been well developed by industry as it would not be cost-effective. For that reason, the most available brace is a thoracolumbosacral orthosis (TLSO).

\subsubsection{TLSO Braces}

TLSO braces are primarily designed to treat scoliosis. The composition of the brace is a hard polyethylene that has been molded to fit a specific patient. For this reason, it is not a good choice of a brace for SMA patients. Firstly, scoliosis is a treatable diagnosis, and patients are prescribed to wear the TLSO brace for a given amount of time each day or week. The TLSO brace is a corrective brace designed to fix the curvature of the spine; however, the brace is not designed to be worn for the extended period of time that SMA patients demand. The TLSO braces are too constrictive and not flexible enough for prolonged usage. Figure $3.1^{4}$ shows a generic TLSO brace, encompassing the entire torso 
in 360 degrees does not allow for much breathability or movement; it does ensure that the patient is safe, however uncomfortable they may be.

Another downside of TLSO braces is the cost. As stated earlier, scoliosis patients only have to use the brace for a prescribed amount of time until the curvature of the spine is corrected; therefore, paying for usually only one brace. On the other hand, and SMA patient will have to purchase a new brace as often as every year, and with TLSO braces at $\$ 4000$ each, it becomes a costly solution on top of the frequent medical visits.

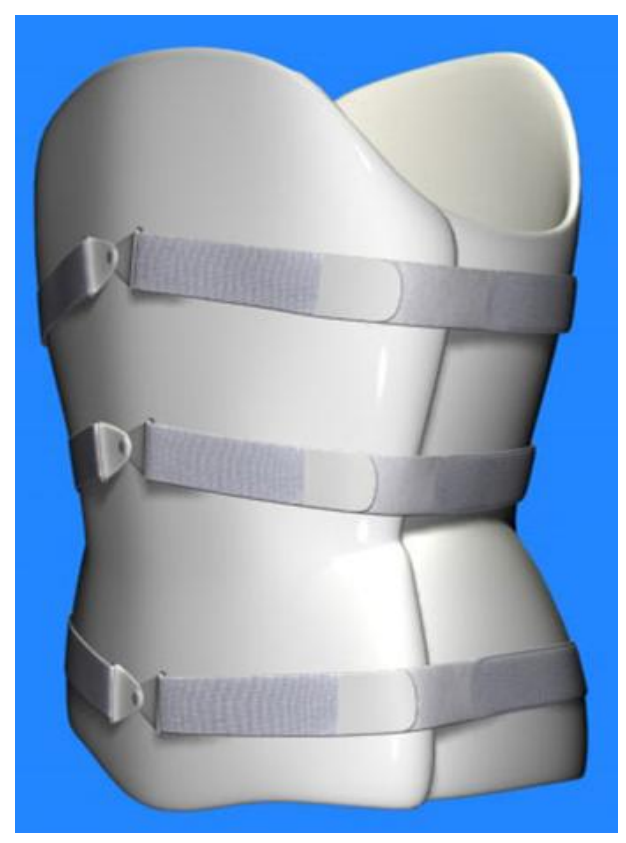

Figure 3.1. A generic TLSO brace is shown. It is made of two parts and provides 360 degrees of support.

\subsection{Goal of Project}

The goal of the project is to develop a more elastomeric and flexible brace for SMA patients without sacrificing the support and safety given by the current TLSO braces. The new brace will be more modular and have the ability to last for longer life stages. Ideally the brace will be less costly than the TLSO braces; however the modular character could help to alleviate some of the expense. The project will be developed in coordination with the Cooper family, who will be providing the test subject for the brace.

Initial ideas focused on creating a series of rectangular or circular PUR pieces and attaching them together to form an adjustable, modular brace. This would allow the brace to be breathable and only apply stress and support in specific areas as determined by the subject. It would also remove the costly individual customization of the mold. The ideal 
material to replace the hard polyethylene of the TLSO braces is a material that has adequate strength and toughness; however still provides some flexibility. Current projects in Dr. Philip Costanzo's research group have focused on using polyurethane elastomers as a binder for insensitive munitions. Those materials also require the same characteristics as the desired brace properties. For the reason that it was the most readily available, cost-effective material available in lab, it was the first material explored.

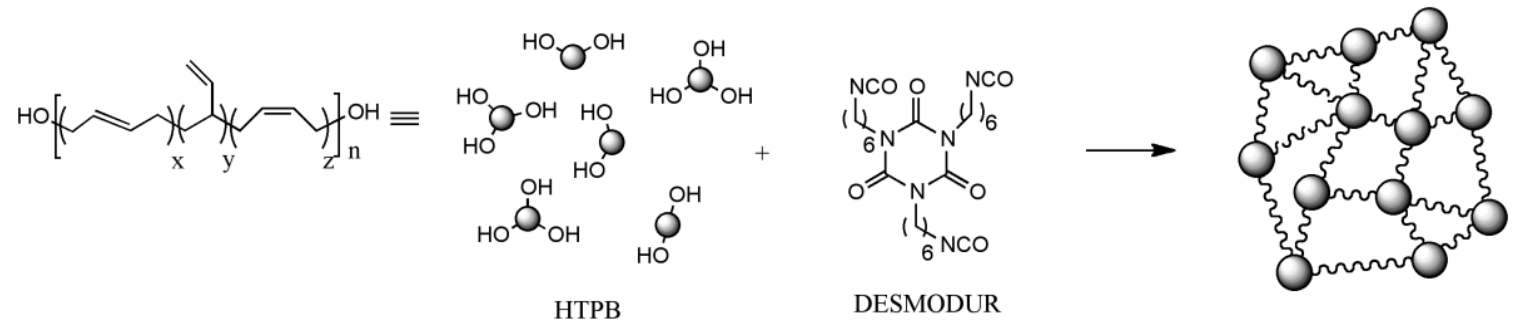

Figure 3.2. The general reaction scheme to form an HTPB polyurethane elastomer is shown.

The basic reaction employed and materials used for the scale-up process are described in detail in Chapter 1, however a schematic is shown in Figure 3.2. Developing elastomers of various thicknesses allowed for the analysis of the scalability of the elastomers to determine the desired thickness of the brace to achieve a certain strength and flexibility. 
3.4. Scale Up Methods and Materials

3.4.1. Materials

R45HTLO from Sartomer, dibutyltin dilaurate and HMDI from Sigma Aldrich, and triethylene tetramine and EPON 828 from the Cal Poly Coatings Lab were all used as received. A Thinky ARE-100 mixer was used for all mixing under $90 \mathrm{~g}$.

3.4.2. RSB-A-5 - Circular Gel

R45HTLO (50 g, $17.85 \mathrm{mmol})$ was added to a disposable weigh cup along with

DBTDL (10 drops), the contents were premixed using a Thinky ARE-100 for 30 seconds. HMDI (3.58 mL, $22.27 \mathrm{mmol}$ ) was added and then the mixture was mixed for 30 more seconds. The gel was poured into a red, polyethylene, disposable lid $(\mathrm{r}=6 \mathrm{~cm}, \mathrm{~h}=1 \mathrm{~cm})$ and allowed to cure at room temperature for 6 hours.

3.4.3. RSB-A-7 - Thicker circular gel

R45HTLO (82 g, $29.29 \mathrm{mmol}$ ) was added to a disposable weigh cup along with DBTDL (16 drops), the contents were premixed using a Thinky ARE-100 for 30 seconds. HMDI (5.88 $\mathrm{mL}, 36.58 \mathrm{mmol})$ was added and then the mixture was mixed for 30 more seconds. The gel was poured into a red, polyethylene, disposable lid $(\mathrm{r}=6 \mathrm{~cm}, \mathrm{~h}=2 \mathrm{~cm})$ and allowed to cure at room temperature for 6 hours.

3.4.4. RSB-A-9 \& RSB-A-11 - Aluminum molds

R45HTLO (82 g, $29.29 \mathrm{mmol}$ ) was added to a disposable weigh cup along with

DBTDL (16 drops), the contents were premixed using a Thinky ARE-100 for 30 seconds. HMDI (5.88 $\mathrm{mL}, 36.58 \mathrm{mmol})$ was added and then the mixture was mixed for 30 more seconds. The gel was poured into the bottom of an epoxy treated aluminum paint can and 
allowed to cure overnight at room temperature (RSB-A-9), and overnight at $60{ }^{\circ} \mathrm{C}$ (RSBA-11).

\subsubsection{RSB-A-15 - Rectangular Elastomer}

R45HTLO (200 g, $71.42 \mathrm{mmol}$ ) was added to a disposable DIXIE cup along with DBTDL (3 drops), the contents were premixed by hand for 5 minutes using an aluminum rod. HMDI (14.96 g, $89.07 \mathrm{mmol}$ ) was added and then the mixture was stirred by hand for an additional 5 minutes to ensure uniform dispersion. The gel was poured into a rectangular silicone mold, which was sprayed with silicone mold release spray and allowed to cure overnight at room temperature.

\subsubsection{RSB-A-17 - Rectangular elastomer w/vacuum}

R45HTLO (200 g, $71.42 \mathrm{mmol}$ ) was added to a disposable DIXIE cup along with DBTDL (3 drops), the contents were premixed by hand for 5 minutes using an aluminum rod. HMDI (14.96 g, $89.07 \mathrm{mmol}$ ) was added and then the mixture was stirred by hand for an additional 5 minutes to ensure uniform dispersion. The gel was poured into a rectangular silicone mold, which was sprayed with silicone mold release spray and vacuum was applied for 10 minutes in an attempt to remove bubbles. The sample was allowed to cure overnight at room temperature. Observations were recorded.

\subsection{7. $\quad$ RSB-A-19 - Copper wire Filler Added}

R45HTLO (200 g, $71.42 \mathrm{mmol}$ ) was added to a disposable DIXIE cup along with DBTDL (3 drops), the contents were premixed by hand for 5 minutes using an aluminum rod. HMDI (14.96 g, $89.07 \mathrm{mmol}$ ) was added and then the mixture was stirred by hand for an additional 5 minutes to ensure uniform dispersion. The silicone mold was lined with copper wire in order to incorporate the copper wire within the polyurethane matrix. 
The gel was poured into the rectangular silicone mold, which was sprayed with silicone mold release spray, and vacuum was applied for 10 minutes in an attempt to remove bubbles. The sample was allowed to cure for 30 minutes at room temperature, allowing for bubbles to escape the matrix, followed by $60{ }^{\circ} \mathrm{C}$ for 24 hours.

\subsection{8. $\quad$ RSB-A-21}

EPON 828 (5 g, 26.3 meq) was added to a disposable weigh cup along with TETA (1.28 g, 8.75mmol). The mixture was stirred via the Thinky ARE-100 for 60 seconds. Small pieces of PUR elastomer were removed at three exit ports of the copper wire in RSB-A-19, marked with the letter C, and EPOXY mixture was applied to fill the void, the sample cured at $60^{\circ} \mathrm{C}$ for 1 hour. EPOXY was added on the surface of three other exit ports and cured at $60{ }^{\circ} \mathrm{C}$ for 1 hour.

\subsubsection{RSB-A-23}

R45HTLO (200 g, $71.42 \mathrm{mmol}$ ) was added to a disposable DIXIE cup along with DBTDL (3 drops), the contents were premixed by hand for 5 minutes using an aluminum rod. HMDI (14.96 g, $89.07 \mathrm{mmol}$ ) was added and then the mixture was stirred by hand for an additional 5 minutes to ensure uniform dispersion. The silicone mold was lined with copper wire in order to incorporate the copper wire within the polyurethane matrix. The gel was poured into the rectangular silicone mold, which was sprayed with silicone mold release spray, and vacuum was applied for 10 minutes in an attempt to remove bubbles. The sample was allowed to cure for 30 minutes at room temperature, allowing for bubbles to escape the matrix, followed by $60{ }^{\circ} \mathrm{C}$ for 24 hours. 


\subsubsection{RSB-A-27 - Incorporation of Directional Strengthener}

EPON 828 (100 g, 472 meq) was added to a disposable DIXIE cup along with TETA (25.6 g, $175 \mathrm{mmol}$ ). The mixture was stirred by hand for five minutes. Sections of RSBA-17 were removed, and the remaining pieces were placed in the siliconee mold at 1 inch and $1 \mathrm{~cm}$ apart. The mixture was poured into the voids and allowed to cure at $60{ }^{\circ} \mathrm{C}$ for 5 hours.

\subsection{Scale up - Results and Discussion}

Various samples were prepared in the 50-200 g scale in an effort to experiment with shape and thickness as well as addressing issues like attachment points and directional strengthening. The initial circular sample prepared, RSB-A-5, did not exhibit the desired physical properties. The sample is shown in Figure 3.3. It should be noted that the sample is torn due to the physical tests it was subjected to. The samples were almost completely void of air bubbles; this can most likely be attributed to the gyroscopic mixing that removed most of the air from the material. It was determined that the circular shape allowed for too many modes of motion; there wasn't any restriction based on dimensions.

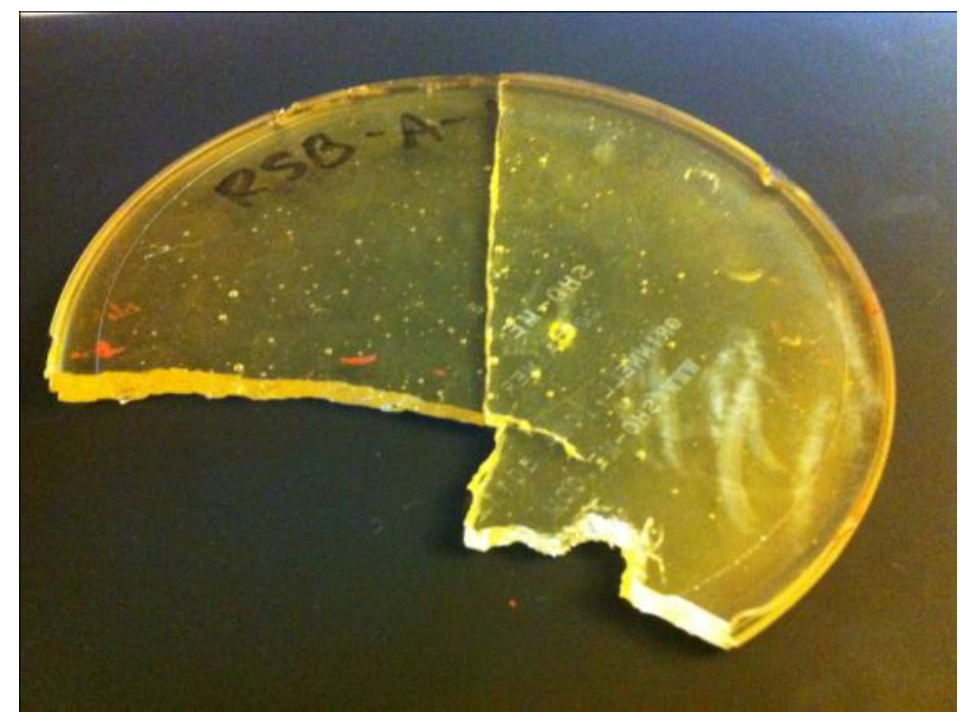

Figure 3.3. RSB-A-5. Round polyethylene gel elastomer. 
The next sample, RSB-A-7 was very similar except the thickness was increased. A sample size of $82 \mathrm{~g}$ was chosen because the limit of overall mass for the Thinky ARE100 is $100 \mathrm{~g}$ of solid or $90 \mathrm{~g}$ of liquid. Other circular samples were prepared but using different vessels. RSB-A-9 and RSB-A-11 were the same formula but they were cured at a different temperature; furthermore, they were cured in a quart-sized aluminum paint can. The vessel for the first two molds, a polyethylene lid, served as a good vessel; the polyurethane elastomer was easily removed without any assistance. However, it was determined that the aluminum substrate had very strong adhesion to the sample. RSB-A-9 and RSB-A-11 were completely destroyed trying to remove them from their mold casings. For this reason it was determined that mold release spray should be used in the future. Despite increasing the thickness, the circular sample was still too flimsy. For this reason, it was decided that rectangular elastomers might be more effective to providing the support needed and would be a better model for the large brace once made. The thickness was also increased again in order to add additional strength.

The rectangular shape proved to be a more effective shape for the development and analysis of the material. RSB-A-15, due to the larger sample size, had to be hand mixed and therefore the catalyst amount was decreased significantly in order to allow for a longer pot life. The viscosity of the samples made it strenuous to mix by hand; therefore in order to ensure thorough mixing, the mixing time was increased from one minute to 57 minutes depending on the sample size. Due to the hand mixing, many bubbles were present during the initial phases. Although many of the bubbles were able to rise to the surface, the presence of the air in the material and the slower cure time caused additional carbon dioxide bubbles to form via decomposition through the carbamic acid side 


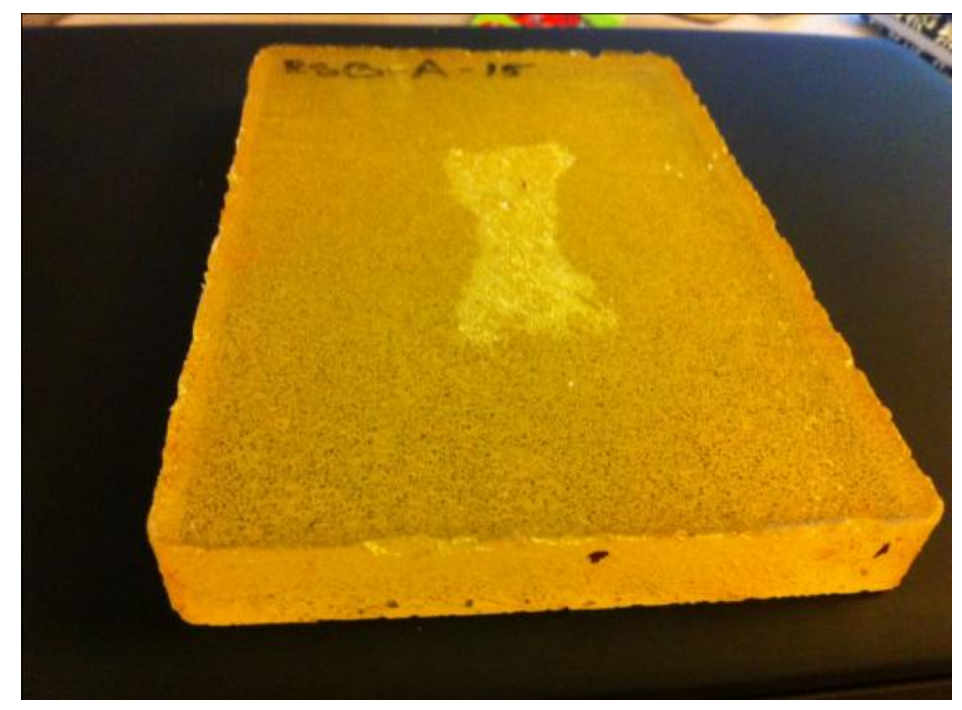

3.4. The $200 \mathrm{~g}$ rectangular sample, RSB-A-15, is shown.

reaction. Figure 3.4 shows sample RSB-A-15. The grouping of bubbles on the top were the bubbles formed during mixing; however a significant number of smaller bubbles are dispersed within the material as well.

In an attempt to remove bubbles from the elastomers, a permeable cage was build around the silicone mold that allowed for a vacuum to be applied to the sample. The vacuum did appreciably decrease the bubbles introduced by hand mixing; however carbon dioxide bubbles still readily formed in the matrix during the cure.

The incorporation of the copper wire into the matrix (RSB-A-19 and RSB-A-23) was necessary because until that point, no feasible method of attachment, either to each other or to some central system was realized. During the initial discussions with the family, it was proposed that the most functional type of brace would be composed of four to six interacting pieces. This would allow for each piece to be independently adjusted and positioned for maximum support and flexibility. Copper wire, though not practical for the brace, gave a good idea of if this design would be feasible. Figure 3.5 shows RSB-A-19 the first formulation with copper wire implementation. The copper wire did not 


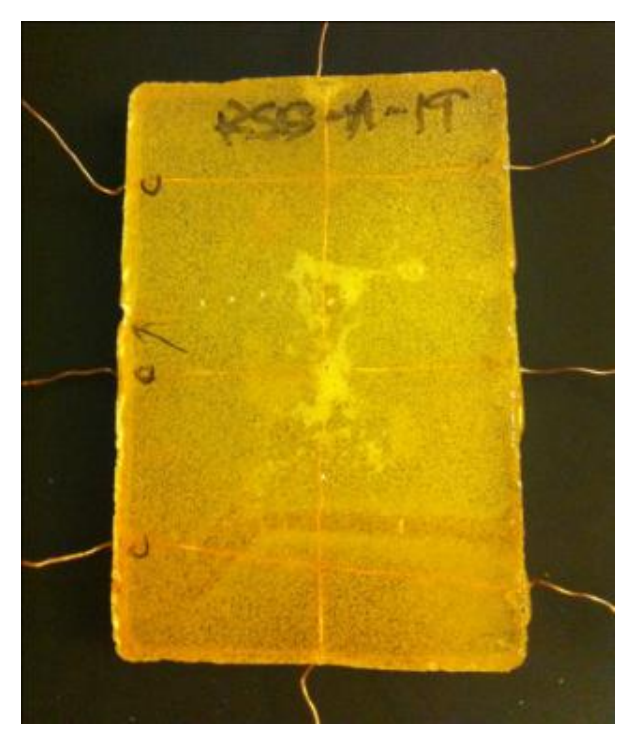

Figure 3.5. RSB-A-19. The incorporation of copper wire into the matrix of a gel appreciably increase the strength of the material; however it did result in the tearing of the polyurethane brace proximal to the exit ports of the wire. For this reason, it was necessary to strengthen the interface points between the polyurethane, wire, and air if this type of attachment system were to be successful. RSB-A-21, a formulated epoxy was applied to the interface locations of RSB-A-19. The 'C'

markings designate that some polyurethane was removed such that the epoxy would fill the hole in a hope to increase the adhesion of the epoxy, and the non ' $\mathrm{C}$ ' locations simply had the epoxy applied to the original surface of the polyurethane, creating an outward bulge. The two interfaces are shown in Figure 3.6. Both submerged and surface epoxy applications were equally successful at stabilizing the interface. It should be noted that
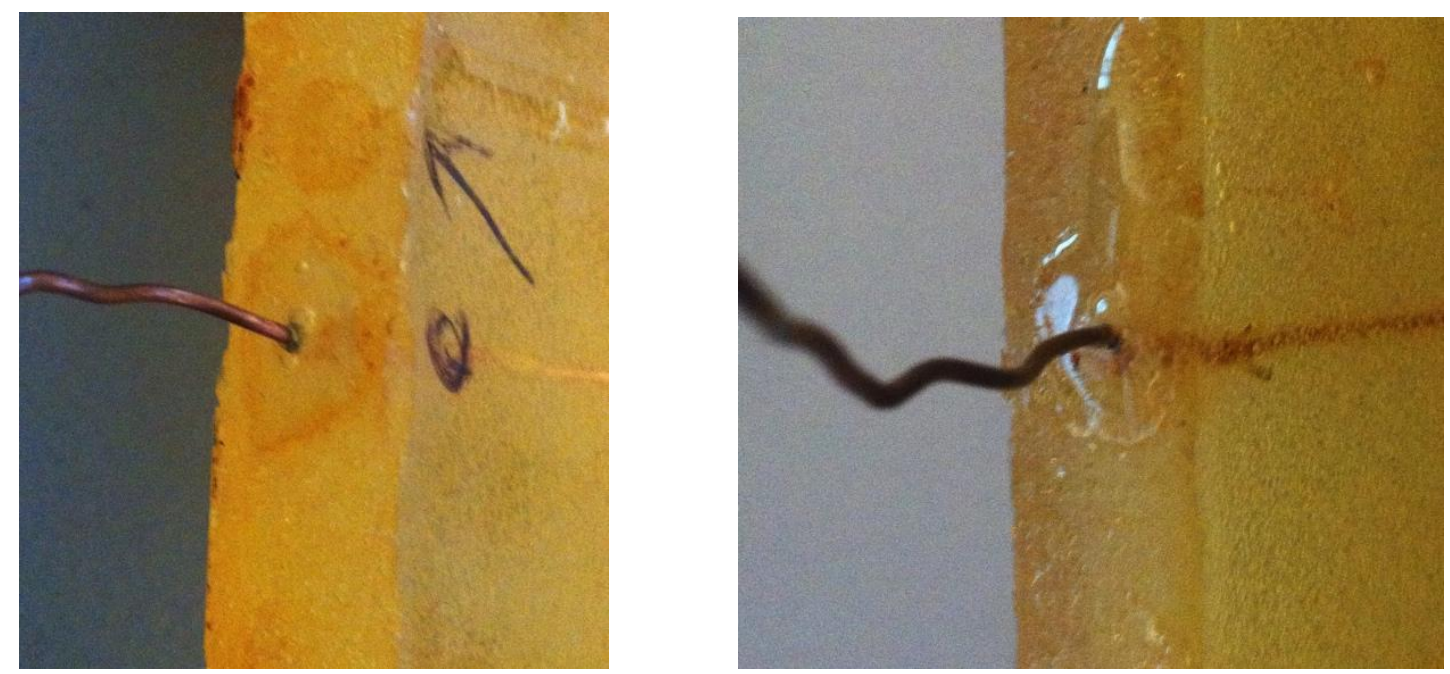

Figure 3.6. The modified copper wire exit ports are shown. On the left, the PUR was removed and replaced by RSB-A-21, while the right shows RSB-A-21 on the surface. 
similar systems of epoxy, polyurethane, and aluminum are used in the aerospace industry as an aircraft coating. ${ }^{5}$ Even with the success of strengthening the attachment ports, it was decided that such a modular system was unfeasible due to the complexity that the number of moving parts would add to the project. Pursuing this option would have also meant a lot of time and money dedicated to developing a more suitable attachment method other than copper wire, which doesn't have the durability to last.

The third major contribution the small-scale testing confirmed at this stage was the interaction between the polyurethane elastomer and epoxy. Although originally seen experienced in the strengthening of the copper attachments, RSB-A-27 was designed to determine how strong various thicknesses of epoxy could be if incorporated into the matrix. Two thicknesses of epoxy were incorporated into RSB-A-17, a 1 inch and a $1 \mathrm{~cm}$ epoxy filler. The PUR regions allowed for flexibility along one direction, while the glassy character of the epoxy filler, regardless of the thickness, provided substantial

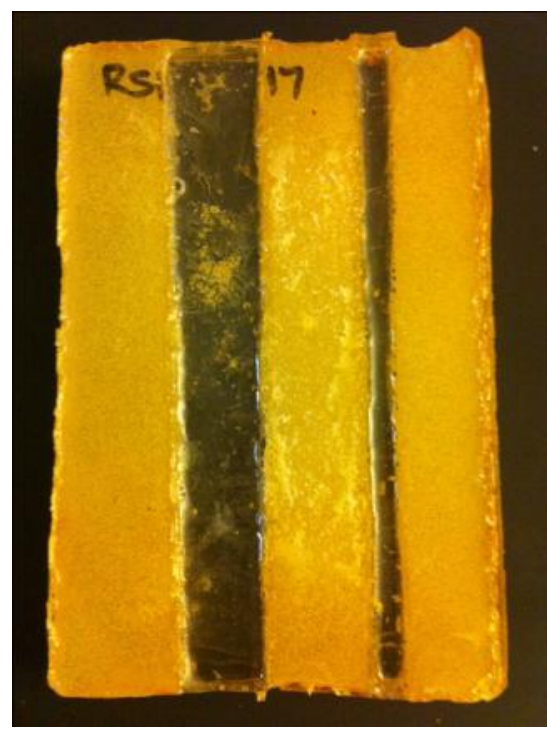

Figure 3.7. Modified RSB-A-17. Rectangular PUR mold with epoxy filler present. rigidity along the other direction. Figure 3.7

shows the modified RSB-A-17 with the directional epoxy included. The adhesion observed between the PUR and epoxy was also notably stronger than either of the materials themselves. This is in agreement with the already established polyurethane epoxy interactions in literature. The polyurethane would sooner tear and the epoxy would sooner crack in half before 
delamination would occur. It is well known that the adhesion between the two materials can be attributed to chemisorption, wherein the epoxy functionalities react with some of the amine groups in the polyurethane matrix. Although the amine groups are only a result of a side reaction, they are more prevalent on the surface due to the interaction of the elastomer with air. This side reaction proved to be quite beneficial as it allowed for the incorporation of epoxy into the brace in areas where extra support might be needed. With the information gathered from the small scale tests, a new brace design was discussed and pursued. 


\subsection{Brace Manufacturing}

\subsubsection{Materials}

\subsubsection{Provided Materials}

A plaster torso mold was received from the family in preparation for the project. Taed M. Studer, CPO, who runs a prosthetics office in San Luis Obispo, CA assisted in providing this mold. Gypsum plaster, or plaster of Paris, was cast around the patient's torso and allowed to dry before removal. Then a hard plaster mold was cast from the plaster of Paris shell. The mold mimics the subject's torso cavity so that a personalized system can be developed without the presence of the patient. Mr. Studer also provided some Velcro strap attachments.

\subsubsection{Acquired Materials}

R45HTLO polyol prepolymer was used as received from Sartomer. Dibutyltin dilaurate (DBTDL) catalyst was used as received from Sigma Aldrich. DESMODUR XP2410 curing agent was used as received from Bayer. Loctite Heavy Duty epoxy, Frost King vinyl foam weatherseal (stickyback, 3/8in thick), Frost King gutter mesh, and wagon bolts with backing were purchased from The Home Depot. Standard clear thumb-tacks ( $1 / 2$ in heads) were purchased from Cal Poly El Corral Bookstore. Silicone mold release spray, sand, and all other materials were readily available in the Cal Poly Polymers and Coatings laboratory. Polyethylene terephthalate sheet (70\% native, $30 \%$ recycled) was provided by the Cal Poly Plastics Processing Lab and thermoforming was performed on a Formech 660. 


\subsubsection{Experimental}

While wearing gloves, R45HTLO (1000 g, $357 \mathrm{mmol})$ was added to a one gallon plastic pail followed by DBTDL (12 drops) and phthalo blue colorant (0.5 mL). The mixture was stirred by hand using an aluminum rod until the colorant was completely dispersed, and then for five additional minutes. Desmodur XP2410 (159.6 g) was added and stirred by hand constantly for seven minutes. The mixture was poured into the outer PET shell and the PET covered inner mold was placed on top and carefully pressed down until contact was made with the thumbtacks. The sample was set in a safe place and allowed to cure at room temperature for 24 hours. This process was repeated for the other side of the brace.

3.6.3. System Design Schematic $-1^{\text {st }}$ Generation Brace

Positive Plaster mold
of torso

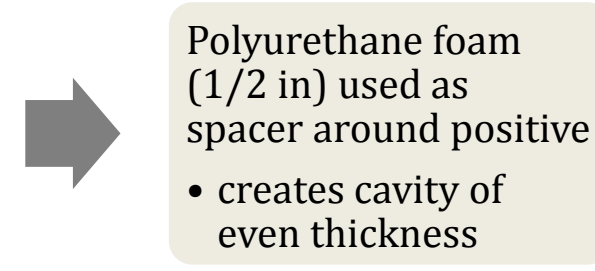

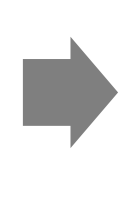

Thermoform PET around foam-covered torso to form disposable outer mold

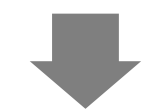

Thumb tacks added as removable filler/spacer between PET sheets

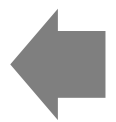

- $1 / 2$ in heads
Diagram brace schematic on PET mold
- Barrier for gel

- End-use comfort

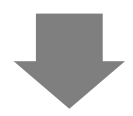

Polyurethane mixed and poured in large PET mold, sandwiched by plaster mold.

\section{- 24 hour cure}

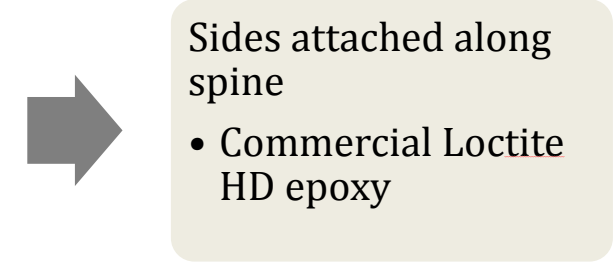

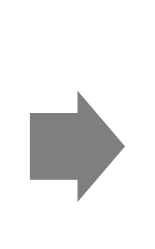

Velcro attachments

- Remove thumb-tacs via Dremel

- 'Wagon' screws and plastic-lock backing

Figure 3.8. A schematic displaying the manufacturing process of the $1^{\text {st }}$ generation brace is shown. 


\subsubsection{Results and Discussion}

3.6.4.1. Thermoforming with polyethylene terephthalate (PET)

Thermoforming is an industrial process in which a plastic can be molded to mimic the shape of a specific object. The thermoform used consisted of a movable platform where the plaster torso brace was placed, a clamp that held the piece of PET plastic, and a heater that softened the PET to above its glass transition temperature (Tg). It should be noted that if the plastic was heated too much, exceeding its crystallization temperature, that it would turn white once cooled due to the semi-crystalline regions in the PET. This did not affect the usability of the materials for this purpose, but is generally considered to be undesirable in applications such as the production of plastic bottles.

Once the PET was heated to above its glass transition, the movable platform, which contained small permeations allowing for a vacuum to remove air from the surroundings, was raised up until contact was made with the PET. The vacuum removed the air around

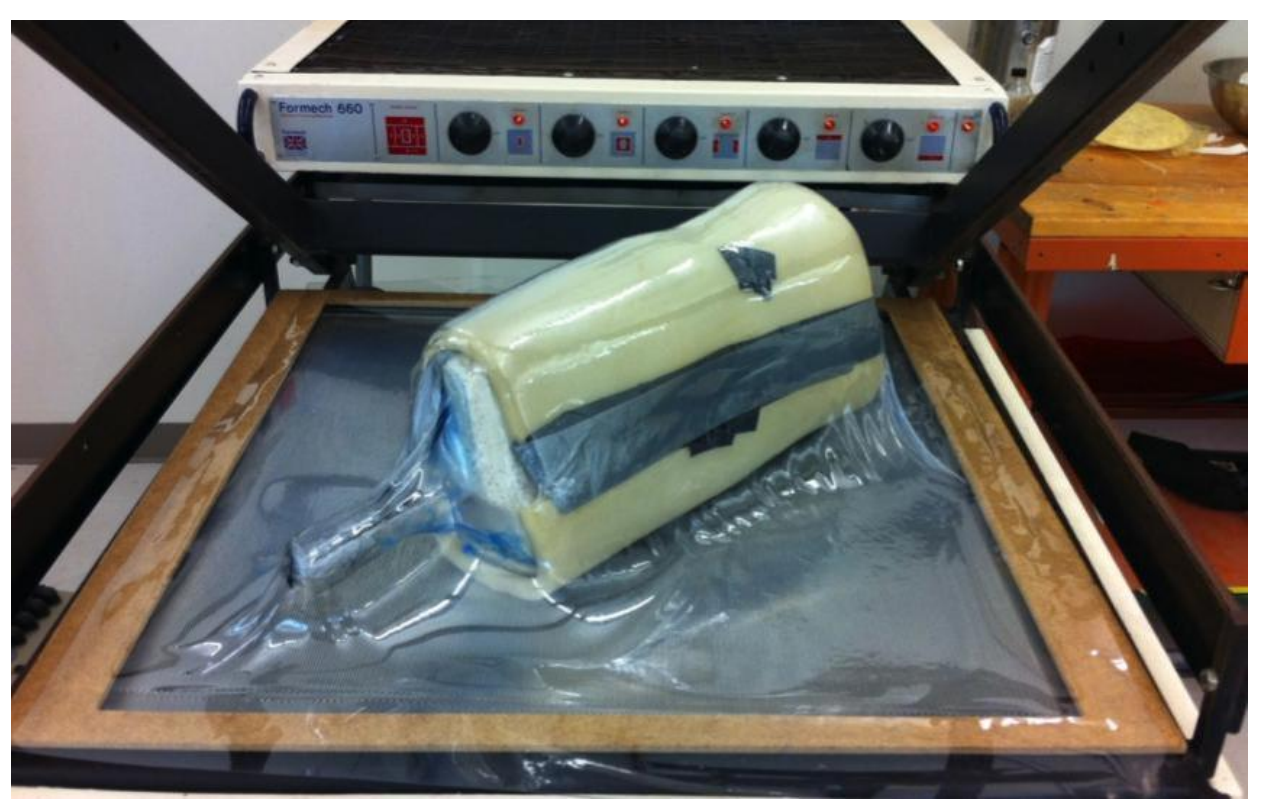

Figure 3.9. The end of the thermoforming process is shown. The PET outer shell has been formed around the expanded plaster mold. 
the plaster brace causing the plastic to form the shape of the plaster torso mold cast. Once the PET was allowed to cool to below its Tg, the sheet was removed and used as a mold.

This process was utilized to form disposable copies of the left, right, front and back of the plaster torso mold. These four pieces were cut down to size and placed over the plaster mold to create a protective barrier around it. Duct tape was used to seal the PET in place around the plaster mold. Polyurethane craft foam, $1 / 2$ in thick, was wrapped around the PET-covered plaster mold to increase its size by a $1 / 2$ " around. The mold with foam was thermoformed again to form outer shells of the left and right sides to which the material for the mold could be poured. Figure 3.9 shows what results at the end of the thermoforming process. A 24"x24" piece of PET has been formed around the expanded plaster torso mold. The clamp has been lifted up in preparation to remove the thermoformed sheet.

\subsubsection{Development Steps $-1^{\text {st }}$ Generation Brace}

To the outer PET sheet, thumbtacks were evenly dispersed such that the heads of the tacks maintained a $1 / 2$ in. thickness between the outer and inner PET shells. Figure 3.10

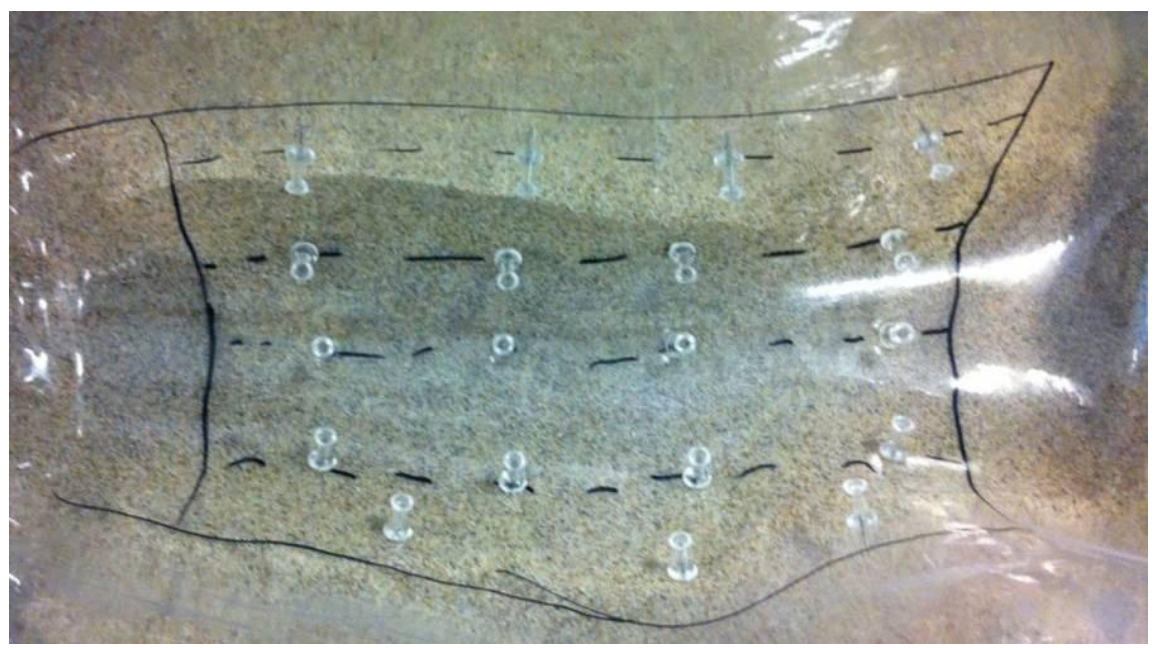

Figure 3.10. The outer PET shell with thumbtack spacers is shown in the tub of sand. The tacks maintain a $1 / 2$ in minimum elastomer thickness. 
shows the thumbtack-lined PET outer shell. The outer shell was placed in a tub of sand and the inner side of the shell was sprayed with silicone mold release spray until lightly coated. The inner PET shell was attached to the heavy plaster torso mold, and taped with duct tape to form a seal. This ensured the protection of the inner plaster mold and also served as a top weight for the gel when curing. Silicone mold release spray was sprayed on the side of the mold that was being formed at that time.

Figure 3.11 shows the tub ready for the polyurethane gel to be poured. The elastomeric mixture was poured between the inner and outer PET shells. Care was taken not to shift the inner mold up or down as it would result in thumbtacks tipping over. The tub containing the sand and curing mold was placed in a safe place and allowed to cure at room temperature for 24 hours.

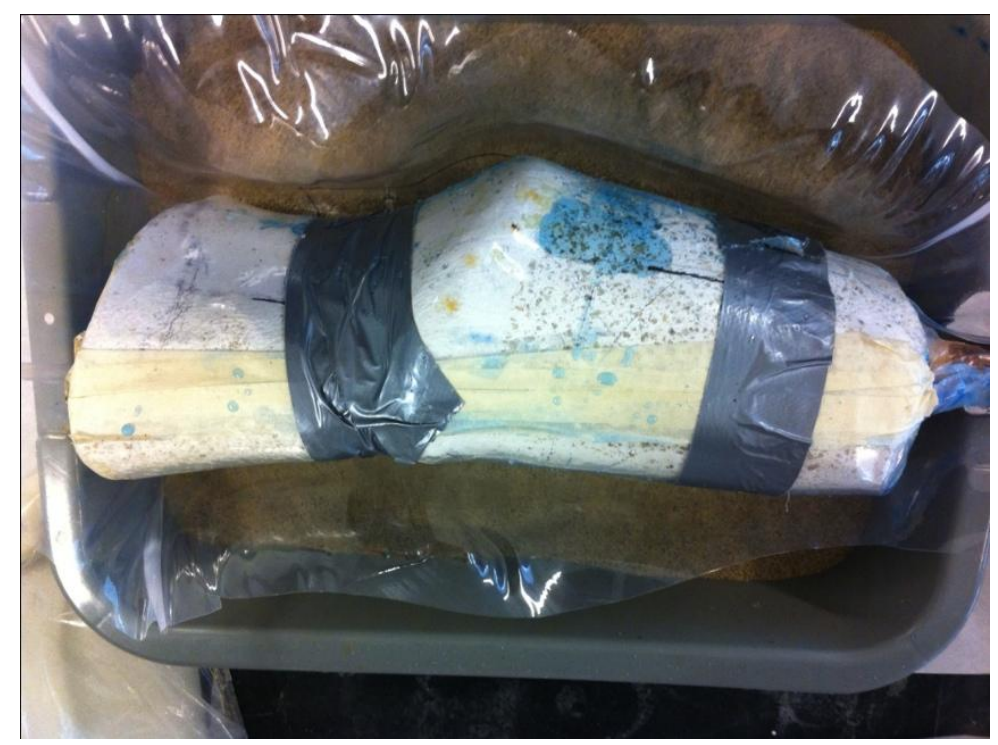

Figure 3.11. An image of the setup immediately before the mold is poured. The plaster is protected by a PET layer, and the inner mold is resting upon the thumbtacks.

Once cured, the inner plaster mold covered in the PET sheet was removed. The cured elastomer mold was turned over and the sharp ends of the thumbtacks were removed 


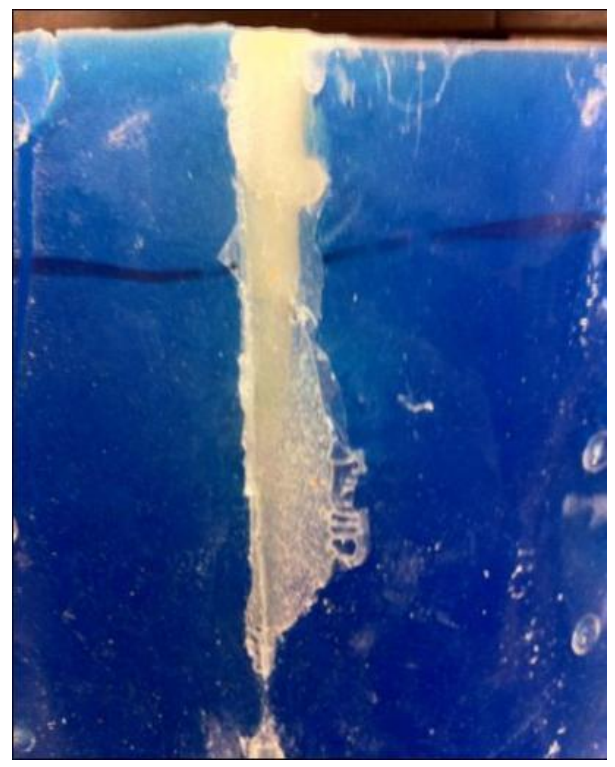

Figure 3.12. The epoxy connecting both sides of the brace is shown. using needle-nose pliers. Once completed, the outer PET sheet was removed leaving either a left-side or right-side mold. The process was repeated with the other side until two molds were formed. Using the plaster mold as a guide, the cured elastomers were cut down to size using a rotary drill. The two sides were attached together along the spine with Loctite epoxy. It should be noted that the epoxy was prepared in small batches and carefully applied between the two sides. Application to the brace

occurred in the last 30 seconds of pot life in an effort to not have the material flow out from between the sides of the brace. Figure 3.12 shows the two sides of the brace with epoxy binding them together.

Epoxy coating was applied along any exposed edge of the brace in a thin layer. This
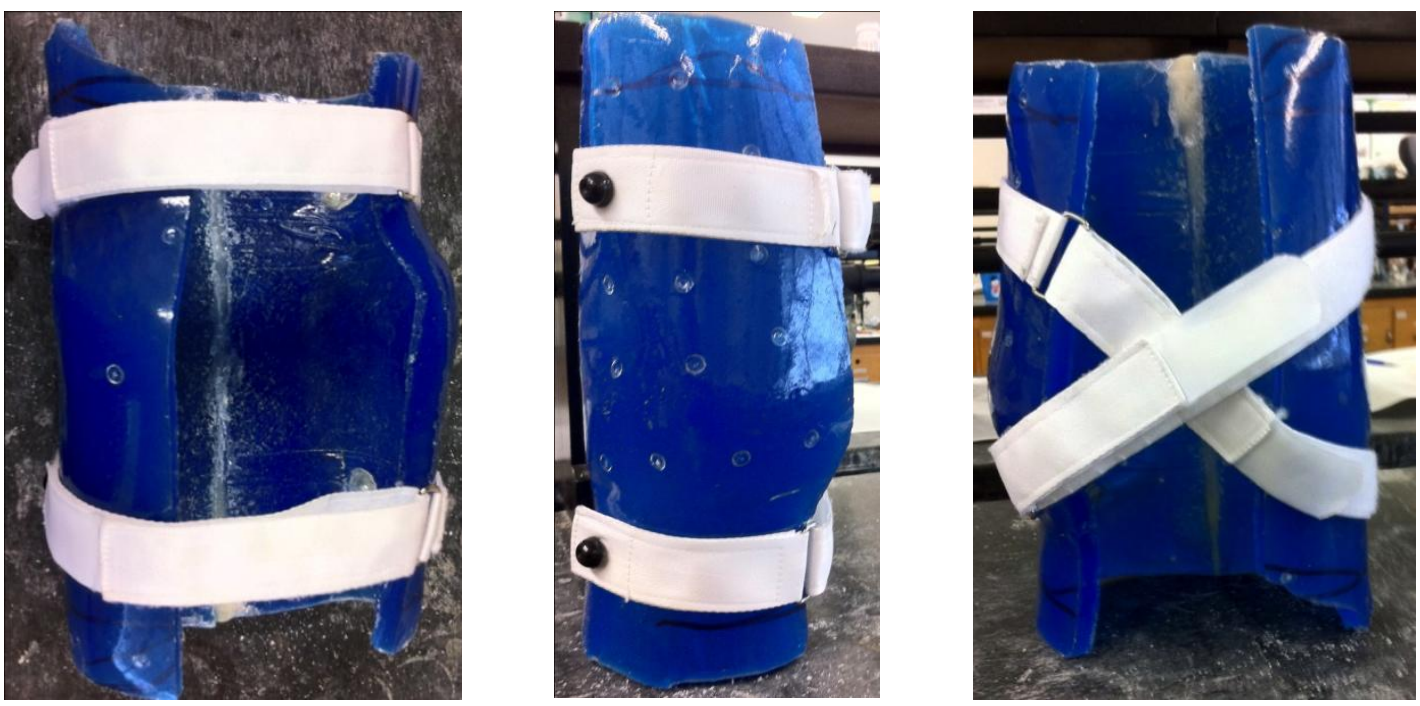

Figure 3.13. The complete first generation brace is shown. Velcro straps are adjustable and can provide semi-modular support. 
was to protect the brace and insure that any blemishes left by the rotary drill were repaired. The layer of epoxy can also be seen at the top of Figure 3.12.

Finally a few of the plastic thumbtacks were removed so that two Velcro straps could be attached. The straps were attached via wagon bolts and plastic locking caps. The wagon bolts allowed the straps to move in a variety of directions. Figure 3.13 shows the completed version of the brace. The Velcro straps can attach horizontally or diagonally, and the front of the brace is kept open in order to allow some room from growth and for the comfort of the patient. After completion, the brace was given to the family for a trial period to evaluate the durability, comfort, and practicality of the brace.

\subsubsection{First Generation Feedback}

After having the new brace for only ten days, the subject's family contacted us to discuss some of the findings and concerns. Firstly, the brace was very well received by the subject. It was a comfortable material and wearing it allowed him the range of motion that was lacking when wearing the TLSO brace. The first concern was that the brace was too large, and therefore the family asked to have the brace adjusted. Upon receiving the brace it was evident that the size was not the only drawback and some changes would be necessary to increase the durability of the brace.

One of the major issues was that the wagon bolts caused very localized stress points when the Velcro straps were used. As a result, the polyurethane elastomer was beginning to tear from the side of the brace up towards the wagon bolt. Secondly, the epoxy around the edges was too hard and would very easily crack and fall off. This had the potential of leaving sharp pieces of epoxy. Lastly, it was determined that the epoxy that connected the sides was too rigid and uncomfortable. 
To improve the durability problem, a variety of fillers were considered - from various fabrics to neoprene that could be added to one side. However, the filler that was the most cost-effective was plastic gutter mesh. The gutter mesh would be able to provide bidirectional strength and also delocalize the movement stress throughout the matrix. Another approach to improving the durability was to delocalize the strap attachment stress using Velcro pieces directly attached to the elastomer using Chicago screws. Also, since the brace was too tall, fitting both too high into the patient's armpits and hitting his legs while in a sitting position, it was determined that the incorporation of some vinyl foam weatherseal into the elastomer could both serve as a barrier to the uncured elastomer while also providing some comfort under the armpits and against the legs.

3.6.4.4. System Design Schematic $-2^{\text {nd }}$ Generation

Positive Plaster mold of torso

Rubber foam Weatherseal added in two layers

-Barrier for gel -End-use comfort

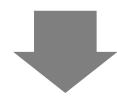

\section{Gutter mesh added to} gel matrix

- Two layers

- Outer and Middle
Polyurethane foam (1/2 in) used as spacer around positive

-creates cavity of even thickness

Thumb tacks added as removable filler/spacer between PET sheets $-1 / 2$ in heads
Thermoform PET

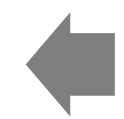

- $1 / 2$ in around foam-covered torso to form

disposable outer mold
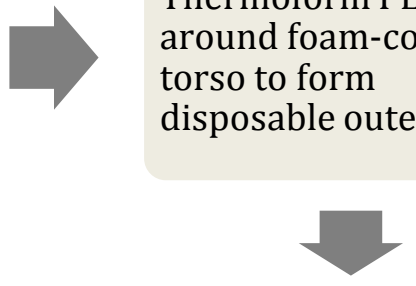

Diagram brace schematic on PET mold
Polyurethane mixed and poured in large PET mold, sandwiched by plaster mold. -24 hour cure
Velcro attachments

-Remove thumb-tacs via Dremel

-'Wagon' screws and plastic-lock backing

Figure 3.14. A block diagram showing the production schematic of the $2^{\text {nd }}$ generation brace is shown. 
3.6.5.1. $\quad 2^{\text {nd }}$ Generation Brace Production

To the outer PET sheet, a schematic was drawn and thumbtacks were evenly dispersed such that the heads of the tacks would maintain a $1 / 2$ in. thickness between the outer and inner PET shells. Vinyl foam weatherseal, $3 / 8$ in. thick was added along the top and bottom edges of the schematic on the outer PET shell to form a wall trapping the elastomer within the barrier. Loctite epoxy was used as extra barrier protection to secure the foam weatherseal wall in place. Figure 3.15 shows the weatherseal

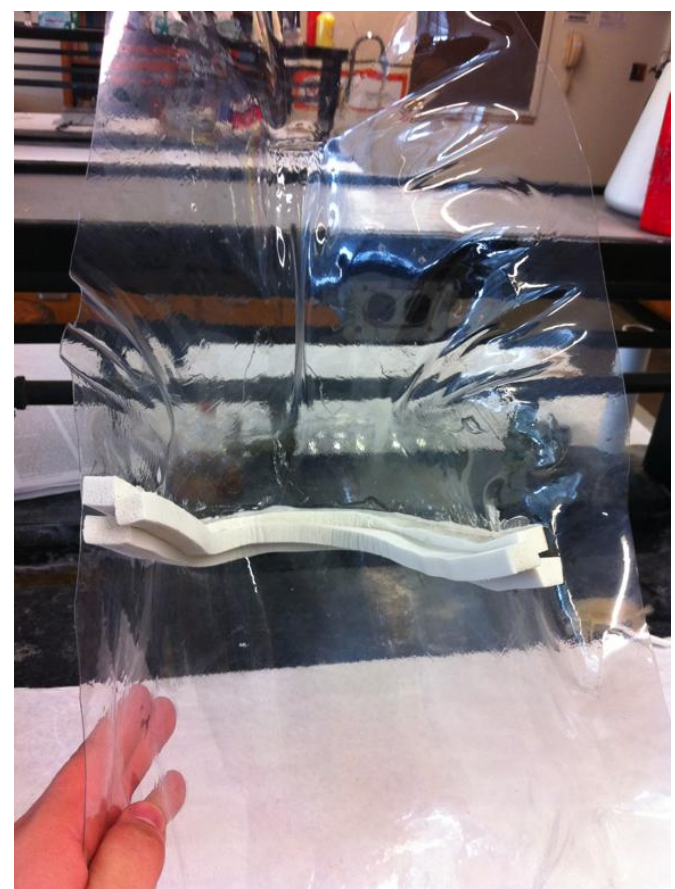

Figure 3.15. The vinyl foam weatherseal, added in two layers is shown. Epoxy is used to seal the layers on the outer side.

with the epoxy added. Plastic gutter mesh was added in two thicknesses. The first layer of gutter mesh was added such that it would be along the outside of the completed brace; the second layer of gutter mesh was suspended on the thumbtacks such that it would be in the

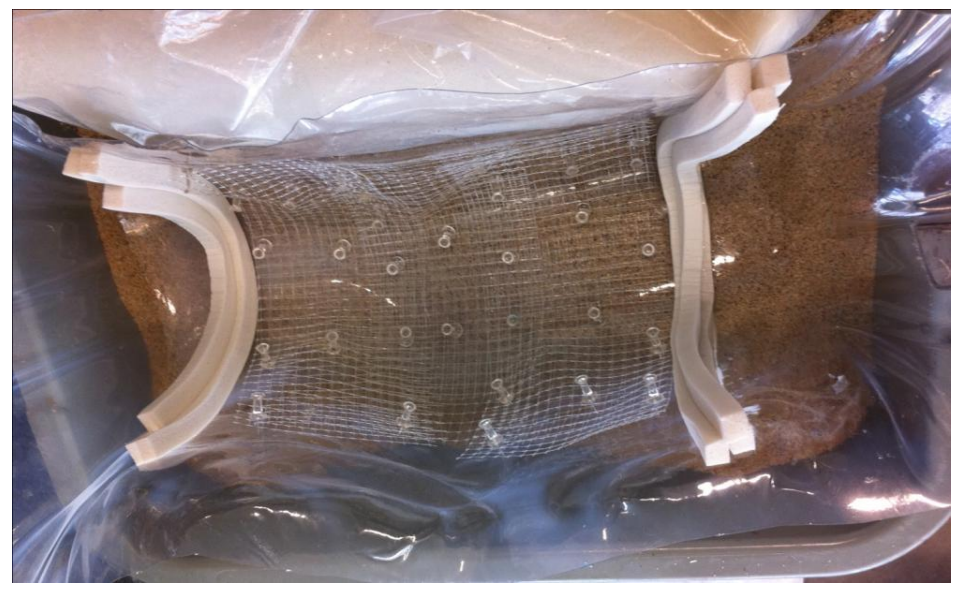

Figure 3.16. The incorporation of gutter mesh is shown. There are two distinct layers, one on the bottom and one suspended in the middle of the thumbtack heads. 
middle of the cured elastomer matrix. Figure 3.16 shows the layers of gutter mesh added to the outer shell of PET. The outer shell was placed in a tub of sand and the inner side of the shell was sprayed with silicone mold release spray until lightly coated. The inner PET shell was attached to the heavy plaster torso mold, and taped with duct tape to form a seal. This ensures the protection of the inner plaster mold and also serves as a top weight for the gel when curing. Silicone mold release spray was sprayed on the side of the mold that was being formed at that time.

Once cured, the inner plaster mold covered in the PET sheet was removed. The cured elastomer mold was turned over and the sharp ends of the thumbtacks were removed using needle-nose pliers. Once completed, the outer PET sheet was removed leaving either a left-side or right-side mold. The process was repeated with the other side until two molds were formed. The resulting molds were shorter than the $1^{\text {st }}$ generation elastomers and also had comfortable foam on the tops and bottoms.

The row of thumbtacks proximal to the spine were removed via rotary drill and a piece of heavy duty Velcro was adhered. The Velcro was attached with six Chicago screws in
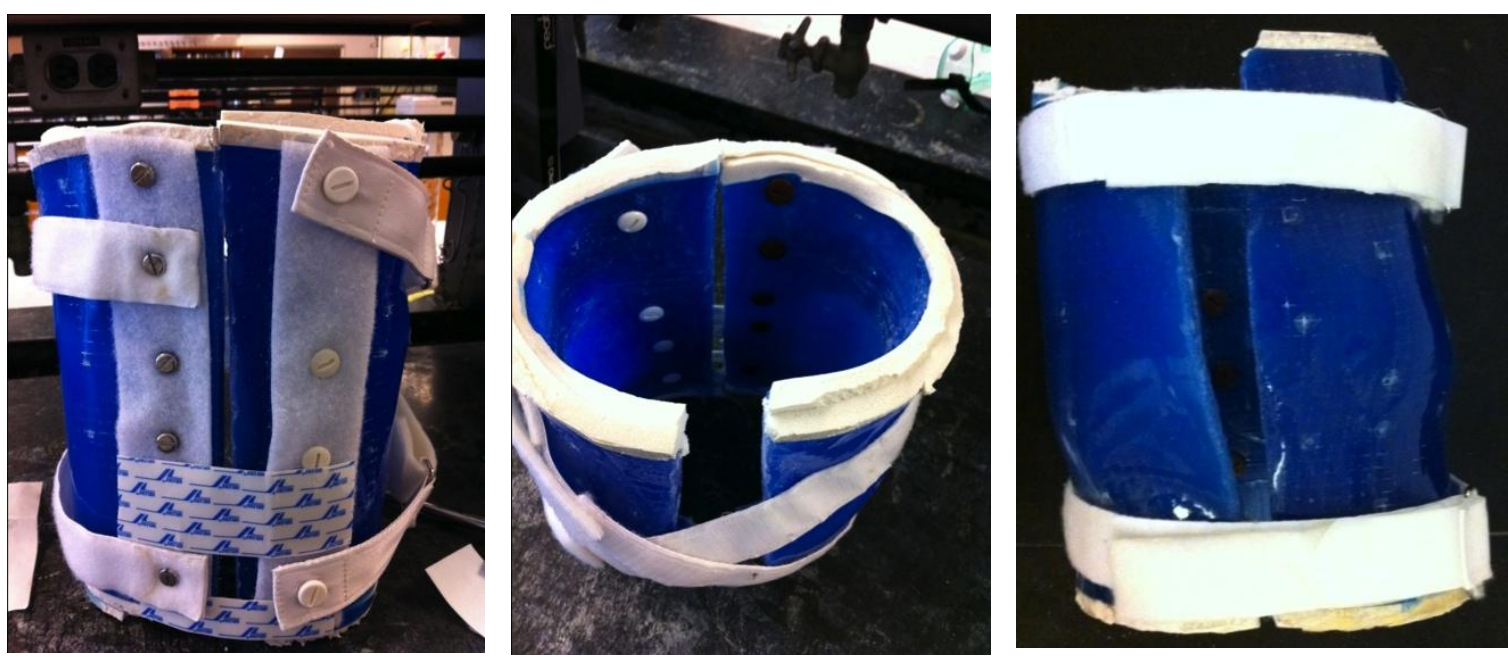

Figure 3.17. The $2^{\text {nd }}$ generation brace is shown from three views: back (left), top-down (middle), and front (right). 
an effort to delocalize the attachment stress. The Velcro straps were attached using the same Chicago screws, and the two sides were connected using six horizontal pieces of heavy duty Velcro. Figure 3.17 shows three images of the finished $2^{\text {nd }}$ generation brace.

\subsubsection{Conclusion}

The subject's family was given the brace, and they appear to be very satisfied with it. The gutter mesh increased the durability of the material by an extraordinary amount, and the delocalization of the attachment stress via the Chicago screws also helps. Perhaps the greatest benefit of the second generation brace is the modularity. With both sides detachable, they can be positioned in any orientation possible or at any difference apart. The Velcro straps are also very modular. They can be attached to any of the 12 screws

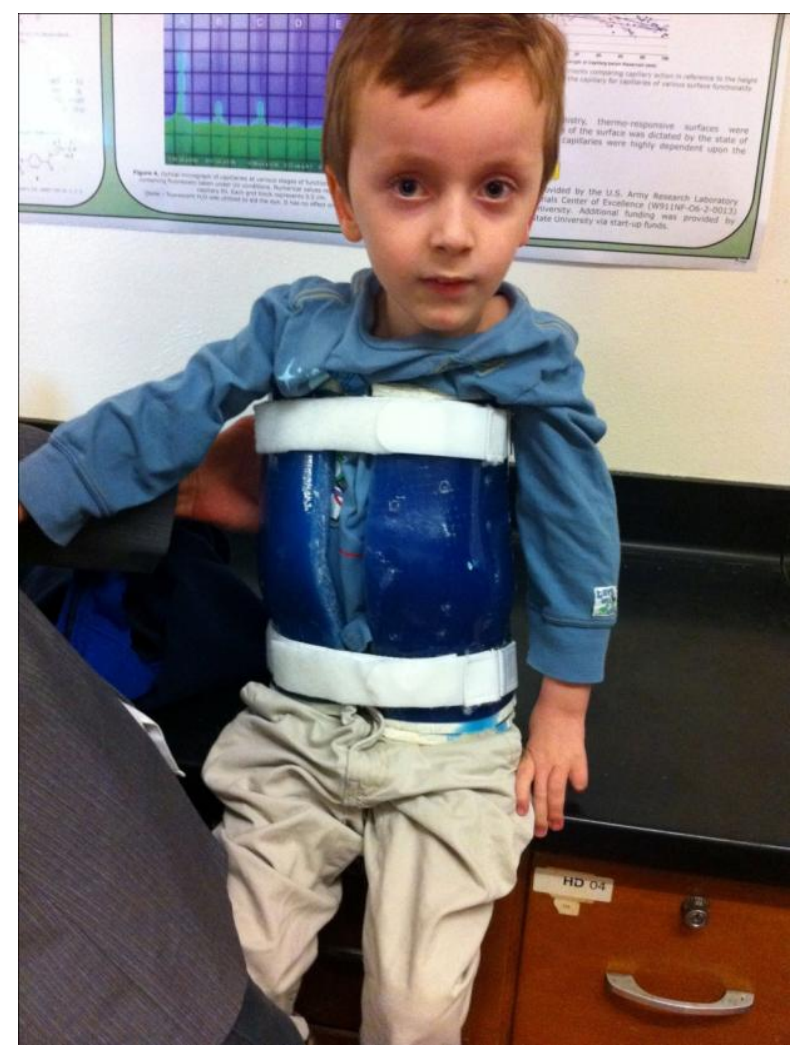

Figure 3.18. The subject wearing the brace. present on the back of the brace, and additional screw holes can be made simply by boring out additional thumbtacks. About two months into having the brace, it was brought in for some minor adjustments; however the patient seems to enjoy wearing it over his TLSO brace due to the increase in the range of motion and the increase in comfort associated with the brace. One enormous bonus to this generation brace is that most of the maintenance can be done at home, without a lab. 
All materials are readily available at Home Depot if new Velcro, straps, or Chicago screws are needed.

\section{REFERENCES}

1. Melki, J., The molecuar bases of spinal muscular atrophy. Curr. Pharm. Des. 2002, 12, 294-298.

2. Orrell, R. W., The relationship of spinal muscular atrophy to motor neuron disease: Investigation of SMN and NAIP gene deletions in sporadic and familial ALS. Journal of Neurological Science 1997, 145, 55-61.

3. Zerres, K., Spinal muscular atrophy - clinical and genetic correlations.

Neuromuscular Disord. 1997, 7, 202-207.

4. Spinal Solutions.net - TLSO - BiLateral Overlap.

http://www.spinalsolution.net/?url=lateral-smoothoverlap\#\&\&ActiveContentUserControl=Lateral+Smooth+Overlap (accessed 5/7/2011).

5. Meier-Weshues, U., Polyurethanes: Coatings, Adhesives and sealants. Vincentz Network: Hannover, 2007; p 344. 


\section{Conclusion of Project}

Polyurethanes have been widely adapted to a wide range of applications since their discovery in the 1940s. The reason for such a versatile array of applications comes from the distinctive chemistry behind the polyurethane. The urethane linkage is a very planar functionality and also allows for hydrogen bonding on the nitrogen and the oxygen that flank the carbonyl group. For this reason, polyurethanes are divided into hard segments and soft segments, both with tunable properties depending on the actual materials used. To synthesize polyurethanes, a polyol is reacted with a polyisocyanate usually in the presence of a tin catalyst. The polyol is the soft segment, and its 'soft' character can be tuned in various ways. For example, if butylene glycol is used as the diol, the soft segment will be very soft because of the freedom of movement in the polyol chain. If a polyol is instead a hydroxyterminated polybutadiene, the double bonds and closely packed side chains allow for a more rigid 'soft' segment. The hard segment can be tuned similarly. For example, an isocyanate such as hexamethylene diisocyanate will allow for much more flexible hard segments than toluene diisocyanate which is very planar.

Learning to tune polyol and polyisocyanate properties is paramount to synthesizing the right polyurethane to the right system.

Polyurethane elastomers are formed when chemical crosslinks are introduced into the matrix, and a gel network results when the functionality of at least one of the reagents is greater than 2 . The speed of the elastomeric cure is also affected by the functionality. The higher the functionalities the higher the concentration of reactive groups within the matrix, and the faster the reaction occurs. Structure and accessibility of reactive groups also play a role in the speed of reaction. Hindered isocyanate groups, such as $2^{\circ}$ groups, 
or hindered alcohol groups will react more slowly than primary groups. Regardless, it is important to understand stoichiometric ratios; if the ratios are uneven, unreacted starting material will be trapped in the matrix. This is normally seen as a disadvantage; however, in some applications having unreacted groups can help with adhesion and chemisorption. Tuning polyurethanes and understanding the macromolecular structure-property relationships are paramount in developing new applications for polyurethanes and polyurethane elastomers.

An undergraduate polymer laboratory experiment was developed utilizing polyurethane elastomers. Three different commercial hydroxyterminated polybutadiene polyols were studied along with three different polyisocyanates. The effect of catalyst concentration on cure time, the effect of crosslinking agent on cure time, and effect of prepolymer structure on properties, and the effect of crosslink density were all built into the undergraduate experiment. Statistical experimental analysis was also built into the experiment. Students learned about experimental design, and the factors that must be considered in order to develop an experimental system that will ensure that the results are statistically significant. A two-way ANOVA was used to analyze both catalyst concentration and curing agent type with respect to cure time. Main effects were determined to exist within both catalyst concentration and cure time, meaning that both factors affected the total cure time. It was also determined that an interaction between catalyst amount and crosslinking agent was present, meaning that the two factors have some sort of symbiotic relationship in relation to cure time. This polymer experiment, which was designed for two, three hour lab periods gives students a very good introductory grasp to network/gel synthesis. 
The principles developed in the undergraduate experiment also were extrapolated to the construction of a polyurethane elastomer brace to be used by patients with spinal muscular atrophy (SMA). SMA is a degenerative disorder that causes atrophy of the spinal muscles as a result of a mutated gene. Although there are varying degrees of severity, the brace was developed for a child who was never able to walk but could sit up straight with the assistance of a brace. The current brace technology, generally designed for scoliosis patients is too stiff and rigid for SMA patients; therefore, the goal was to develop a brace that gave the child equivalent support to the TLSO brace, but also allowed him some freedom of motion.

The elastomeric brace went through two generations of development and feedback from the family, and now the child is in possession of the final brace. This new brace gives the child that extra mobility. The ability to raise his arms and reach out and grab objects without causing discomfort has been restored, and the brace is very modular, so it is able to increase its size as the child grows, saving the family a significant amount of money.

It is truly amazing what can and has been accomplished by scientific advancements. New applications for plastics are still being developed today, and it is only through properly preparing students with the right theory in the classroom and the right practical steps in the laboratory that will allow new innovations to be made such as a brace for a child in need. 
APPENDIX A - Raw Data

Table A1- Effect of catalyst amount on cure time

\begin{tabular}{|c|c|c|c|c|c|c|}
\hline \multicolumn{1}{|c|}{} & \multicolumn{6}{c|}{ Time(min) } \\
\cline { 2 - 7 } & Amount of DBTDL & 0 & 5 & 15 & 30 & 60 \\
\hline \multirow{3}{*}{ Qualitative } & 0 drops & 0 & 0 & 0 & 0 & 0 \\
Viscosity & 10 drops & 0 & 3 & 5 & 7 & 9 \\
& 60 drops & 1 & 4 & 8 & 9 & 9 \\
& 120 drops & 1 & 4 & 8 & 8 & 9 \\
\hline
\end{tabular}

Table A2 - Effect of curing agent on cure time

\begin{tabular}{|c|c|c|c|c|c|c|}
\hline \multicolumn{1}{|c|}{} & \multicolumn{5}{c|}{ Time (min) } \\
\cline { 2 - 7 } & Sample & 0 & 5 & 15 & 30 & 60 \\
\hline \multirow{2}{*}{ Qualitative } & IPDI & 0 & 2 & 4 & 6 & 8 \\
Viscosity & HMDI & 1 & 4 & 9 & 10 & 10 \\
& XP 2410 & 1 & 9 & 10 & 10 & 10 \\
\hline
\end{tabular}

Table A3 - Swelling Raw Data

\begin{tabular}{|c|ccc|cccc|ccc|}
\hline & \multicolumn{3}{|c|}{$0.75: 1.0$} & \multicolumn{3}{c|}{$0.90: 1.0$} & \multicolumn{3}{c|}{$1.0: 1.0$} \\
\cline { 2 - 10 } Time (min) & Acetone & THF & MeOH & Acetone & THF & MeOH & Acetone & THF & MeOH \\
\hline \hline 0 & 4.24 & 4.43 & 4.21 & 4.70 & 4.32 & 4.10 & 4.44 & 4.62 & 3.86 \\
5 & 4.29 & 5.02 & 4.22 & 4.78 & 4.87 & 4.13 & 4.86 & 5.31 & 3.88 \\
10 & 4.36 & 5.73 & 4.25 & 4.82 & 5.18 & 4.15 & 4.90 & 5.73 & 3.90 \\
20 & 4.41 & 6.75 & 4.28 & 4.83 & 5.51 & 4.15 & 4.95 & 6.16 & 3.90 \\
40 & 4.44 & 7.67 & 4.28 & 4.92 & 6.50 & 4.16 & 5.03 & 6.64 & 3.91 \\
60 & 4.52 & 8.67 & 4.31 & 4.97 & 7.20 & 4.17 & 5.09 & 7.13 & 3.92 \\
90 & 4.59 & 10.16 & 4.31 & 5.19 & 8.25 & 4.18 & 5.15 & 8.36 & 3.92 \\
120 & 4.63 & 11.65 & 4.33 & 5.68 & 9.49 & 4.18 & 5.22 & 9.10 & 3.92 \\
\hline
\end{tabular}


APPENDIX B - Statistical Output

$$
\text { 3/14/2010 9:50:27 PM }
$$

Test for Equal Variances: TIME versus CATALYST, CURING AGENT

95\% Bonferroni confidence intervals for standard deviations

CURING

CATALYST AGENT N Lower StDev Upper

$\begin{array}{lllll}5 & \text { HMDI } 4 & 1.7979 & 3.8622 & 29.272\end{array}$

$\begin{array}{lllll}5 & \text { IPDI } 4 & 10.4808 & 22.5148 & 170.642\end{array}$

20 HMDI $4 \quad 1.5381 \quad 3.3040 \quad 25.042$

$\begin{array}{lllll}20 & \text { IPDI } 4 & 6.0337 & 12.9615 & 98.237\end{array}$

35 HMDI $4 \quad 1.3438 \quad 2.8868 \quad 21.879$

$35 \quad$ IPDI $4 \quad 4.3895 \quad 9.4296 \quad 71.468$

$50 \quad$ HMDI $4 \quad 2.0948 \quad 4.5000 \quad 34.106$

$\begin{array}{lllll}50 & \text { IPDI } 4 & 3.6158 & 7.7675 & 58.870\end{array}$

Bartlett's Test (Normal Distribution)

Test statistic $=19.81, \mathrm{p}$-value $=0.006$

Levene's Test (Any Continuous Distribution)

Test statistic $=2.08, \mathrm{p}$-value $=0.085$

Test for Equal Variances: TIME versus CATALYST, CURING AGENT

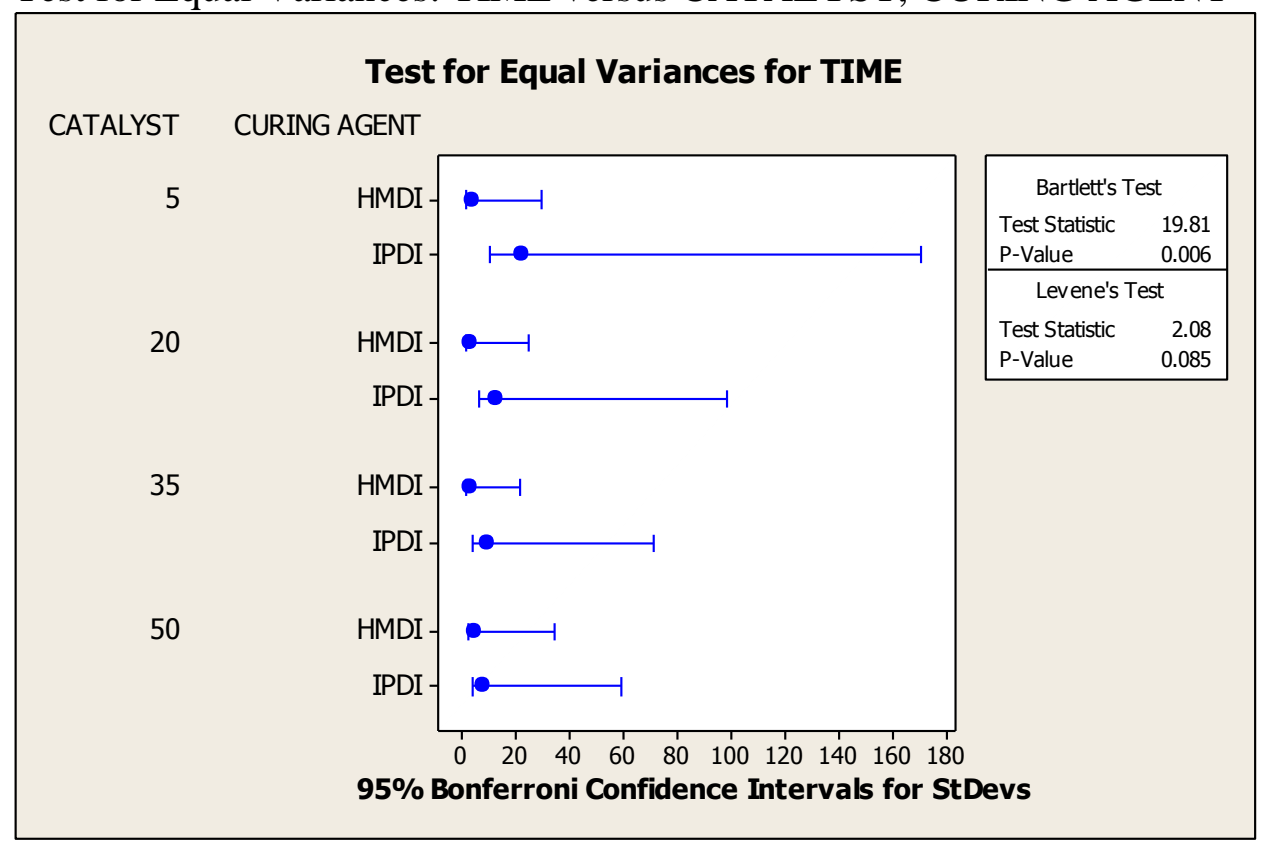


General Linear Model: TIME versus CATALYST, CURING AGENT

Factor Type Levels Values

CATALYST fixed $45,20,35,50$

CURING AGENT fixed 2 HMDI, IPDI

Analysis of Variance for TIME, using Adjusted SS for Tests

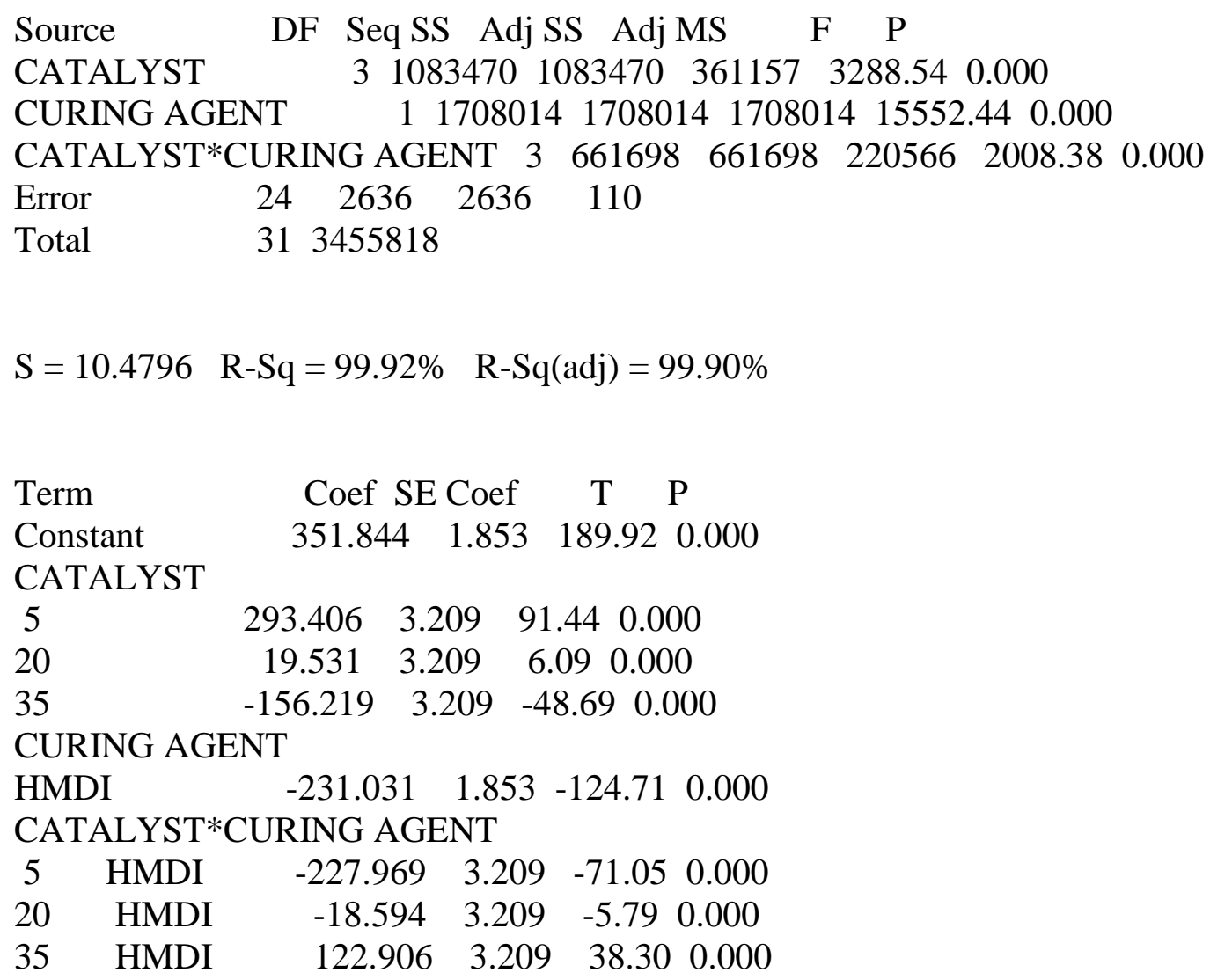

Unusual Observations for TIME

Obs TIME Fit SE Fit Residual St Resid

$\begin{array}{llllll}18 & 1132.00 & 1104.25 & 5.24 & 27.75 & 3.06 \mathrm{R}\end{array}$

$\begin{array}{llllll}20 & 1077.00 & 1104.25 & 5.24 & -27.25 & -3.00 \mathrm{R}\end{array}$

$\mathrm{R}$ denotes an observation with a large standardized residual. 
Expected Mean Squares, using Adjusted SS

\begin{tabular}{lll}
\multicolumn{4}{c}{$\begin{array}{c}\text { Expected Mean } \\
\text { Square for }\end{array}$} \\
Source & Each Term \\
1 & CATALYST & $(4)+\mathrm{Q}[1,3]$ \\
2 & CURING AGENT & $(4)+\mathrm{Q}[2,3]$ \\
3 & CATALYST*CURING AGENT & $(4)+$ Q[3] \\
4 & Error & (4)
\end{tabular}

Error Terms for Tests, using Adjusted SS

\begin{tabular}{lllll}
\multicolumn{4}{c}{ Error Synthesis } \\
Source & Error DF MS of Error MS \\
1 & CATALYST & 24.00 & 110 & $(4)$ \\
2 & CURING AGENT & 24.00 & 110 & (4) \\
3 & CATALYST*CURING AGENT & 24.00 & 110 & (4)
\end{tabular}

Variance Components, using Adjusted SS

\begin{tabular}{|c|c|c|c|}
\hline \multicolumn{4}{|c|}{ Estimated } \\
\hline \multirow{2}{*}{$\begin{array}{l}\text { Sour } \\
\text { Ero }\end{array}$} & Val & & \\
\hline & 109. & & \\
\hline \multicolumn{4}{|c|}{ Least Squares Means for TIME } \\
\hline \multicolumn{4}{|c|}{ CATALYST*CURING } \\
\hline \multicolumn{2}{|c|}{ AGENT } & Mean & SE Mean \\
\hline 5 & HMDI & 186.25 & 5.240 \\
\hline 5 & IPDI & 1104.25 & 5.240 \\
\hline 20 & HMDI & 121.75 & 5.240 \\
\hline 20 & IPDI & 621.00 & 5.240 \\
\hline 35 & HMDI & 87.50 & 5.240 \\
\hline 35 & IPDI & 303.75 & 5.240 \\
\hline 50 & HMDI & 87.75 & 5.240 \\
\hline 50 & IPDI & 302.50 & 5.240 \\
\hline
\end{tabular}

Tukey Simultaneous Tests

Response Variable TIME

All Pairwise Comparisons among Levels of CATALYST*CURING AGENT

CATALYST $=5$ 
CURING AGENT = HMDI subtracted from:

CURING Difference SE of Adjusted

CATALYST AGENT of Means Difference T-Value P-Value

$\begin{array}{llllll}5 & \text { IPDI } & 918.00 & 7.410 & 123.88 & 0.0000\end{array}$

$20 \quad$ HMDI $\quad-64.50 \quad 7.410 \quad-8.70 \quad 0.0000$

$\begin{array}{llllll}20 & \text { IPDI } & 434.75 & 7.410 & 58.67 & 0.0000\end{array}$

$35 \quad$ HMDI $\quad-98.75 \quad 7.410 \quad-13.33 \quad 0.0000$

$\begin{array}{llllll}35 & \text { IPDI } & 117.50 & 7.410 & 15.86 & 0.0000\end{array}$

$\begin{array}{llllll}50 & \text { HMDI } & -98.50 & 7.410 & -13.29 & 0.0000\end{array}$

$\begin{array}{llllll}50 & \text { IPDI } & 116.25 & 7.410 & 15.69 & 0.0000\end{array}$

CATALYST $=5$

CURING AGENT = IPDI subtracted from:

CURING Difference SE of Adjusted

CATALYST AGENT of Means Difference T-Value P-Value

$20 \quad$ HMDI $\quad-982 \quad 7.410 \quad-132.6 \quad 0.0000$

$\begin{array}{llllll}20 & \text { IPDI } & -483 & 7.410 & -65.2 & 0.0000\end{array}$

35 HMDI $\quad-1017 \quad 7.410 \quad-137.2 \quad 0.0000$

$\begin{array}{llllll}35 & \text { IPDI } & -800 & 7.410 & -108.0 & 0.0000\end{array}$

$\begin{array}{llllll}50 & \text { HMDI } & -1017 & 7.410 & -137.2 & 0.0000\end{array}$

$\begin{array}{llllll}50 & \text { IPDI } & -802 & 7.410 & -108.2 & 0.0000\end{array}$

CATALYST $=20$

CURING AGENT = HMDI subtracted from:

CURING Difference SE of Adjusted

CATALYST AGENT of Means Difference T-Value P-Value

$\begin{array}{llllll}20 & \text { IPDI } & 499.25 & 7.410 & 67.373 & 0.0000\end{array}$

$35 \quad$ HMDI $\quad-34.25 \quad 7.410 \quad-4.622 \quad 0.0024$

$\begin{array}{llllll}35 & \text { IPDI } & 182.00 & 7.410 & 24.561 & 0.0000\end{array}$

$\begin{array}{llllll}50 & \text { HMDI } & -34.00 & 7.410 & -4.588 & 0.0026\end{array}$

$\begin{array}{llllll}50 & \text { IPDI } & 180.75 & 7.410 & 24.392 & 0.0000\end{array}$

CATALYST $=20$

CURING AGENT = IPDI subtracted from:

CURING Difference SE of Adjusted

CATALYST AGENT of Means Difference T-Value P-Value

$\begin{array}{llllll}35 & \text { HMDI } & -533.5 & 7.410 & -72.00 & 0.0000\end{array}$

$\begin{array}{llllll}35 & \text { IPDI } & -317.3 & 7.410 & -42.81 & 0.0000\end{array}$

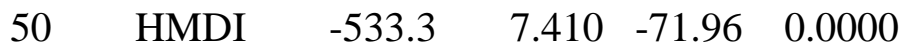


CATALYST $=35$

CURING AGENT $=$ HMDI subtracted from:

CURING Difference SE of Adjusted

CATALYST AGENT of Means Difference T-Value P-Value

$\begin{array}{llllll}35 & \text { IPDI } & 216.250 & 7.410 & 29.1826 & 0.0000\end{array}$

$\begin{array}{llllll}50 & \text { HMDI } & 0.250 & 7.410 & 0.0337 & 1.0000\end{array}$

$\begin{array}{llllll}50 & \text { IPDI } & 215.000 & 7.410 & 29.0140 & 0.0000\end{array}$

CATALYST $=35$

CURING AGENT = IPDI subtracted from:

CURING Difference SE of Adjusted

CATALYST AGENT of Means Difference T-Value P-Value

$\begin{array}{llllll}50 & \text { HMDI } & -216.0 & 7.410 & -29.15 & 0.0000\end{array}$

$\begin{array}{llllll}50 & \text { IPDI } & -1.3 & 7.410 & -0.17 & 1.0000\end{array}$

CATALYST $=50$

CURING AGENT $=$ HMDI subtracted from:

CURING Difference SE of Adjusted

CATALYST AGENT of Means Difference T-Value P-Value $\begin{array}{llllll}50 & \text { IPDI } & 214.8 & 7.410 & 28.98 & 0.0000\end{array}$

Residual Plots for TIME

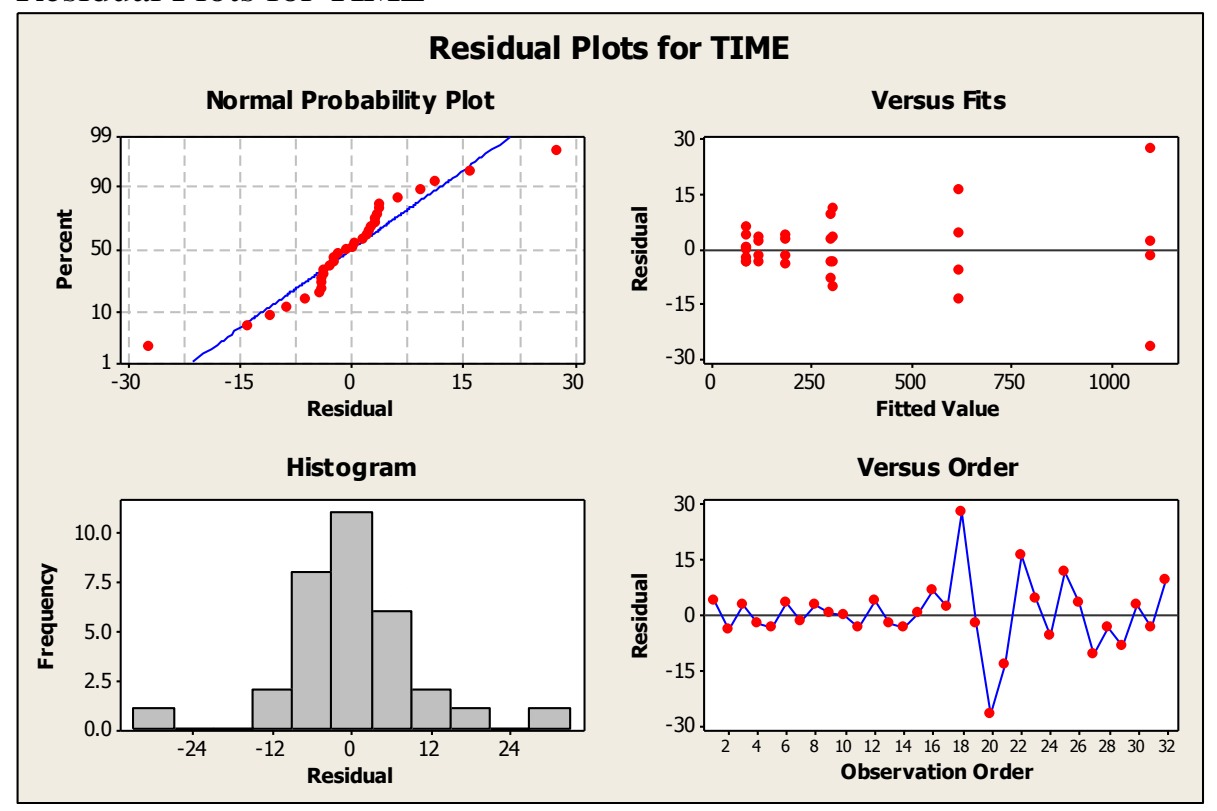


Main Effects Plot for TIME

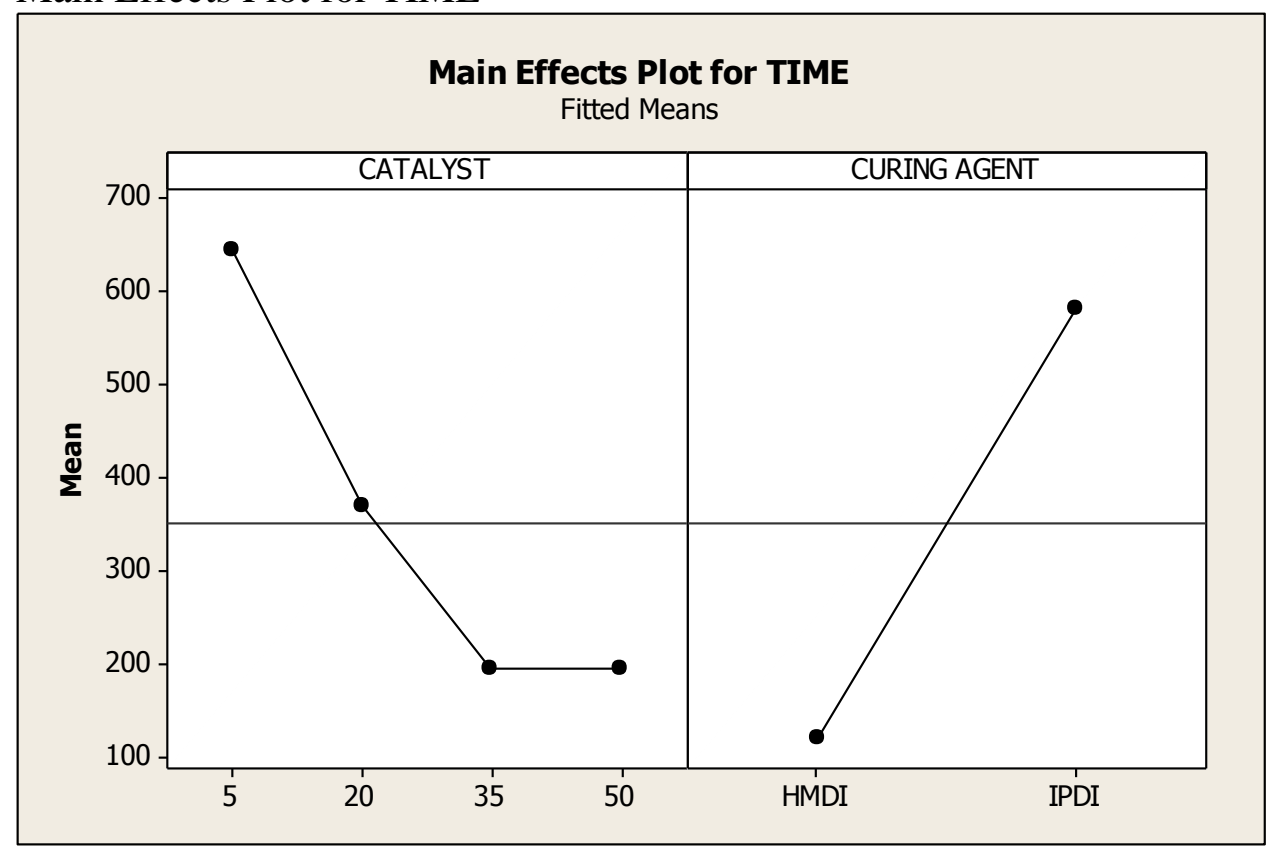

Interaction Plot for TIME

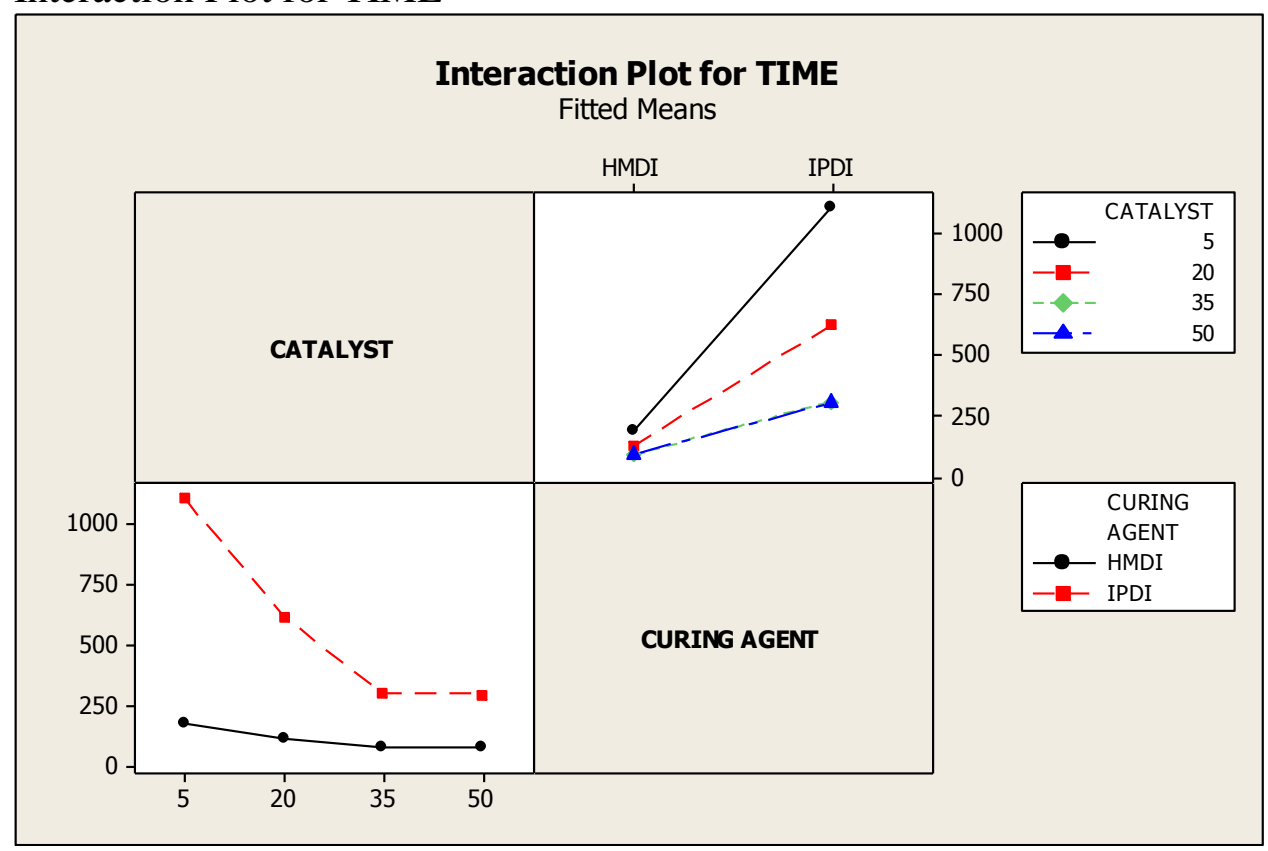

